WSRC-RP-94-927

Rev 0

\title{
Final Report on Testing of Off-Gas Treatment Technologies for Abatement of Atmospheric Emissions of Chlorinated Volatile Organic Compounds (U)
}

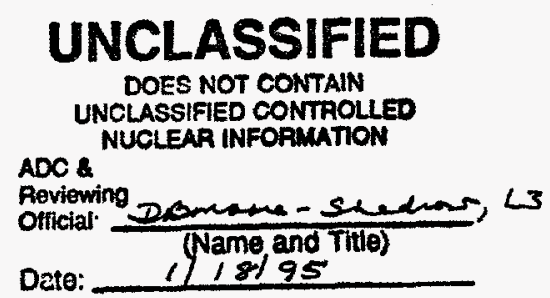

Westinghouse Savannah River Company

Savannah River Site

Aiken, SC 29808

Prepared for the U.S. Department of Energy under Contract No. DE-AC09-89SR18035

This work was funded by the Office of Technology Development, within DOE's Office of Environmental Management, under the VOC's in Non-Arid Soils Integrated Demonstration 


\section{DISCLAIMER}

This report was prepared as an account of work sponsored by an agency of the United States Government. Neither the United States Government nor any agency thereof, nor any of their employees, makes any warranty, express or implied, or assumes any legal liability or responsibility for the accuracy, completeness, or usefulness of any information, apparatus, product, or process disclosed, or represents that its use would not infringe privately owned rights. Reference herein to any specific commercial product, process, or service by trade name, trademark, manufacturer, or otherwise does not necessarily constitute or imply its endorsement, recommendation, or favoring by the United States Government or any agency thereof. The views and opinions of authors expressed herein do not necessarily state or reflect those of the United States Government or any agency thereof.

This report has been reproduced directly from the best available copy.

Available to DOE and DOE contractors from the Office of Scientific and Technical Information, P.O. Box 62, Oak Ridge, TN 37831; prices available from (615) 576-8401.

Available to the public from the National Technical Information Service, U.S. Department of Commerce, 5285 Port Royal Road, Springfield, VA 22161. 


\section{DISCLAIMER}

Portions of this document may be illegible in electronic image products. Images are produced from the best available original document. 
WSRC-RP-94-927

Rev 0

September, 1994

Final Report on Testing of Off-Gas Treatment Technologies for Abatement of Atmospheric Emissions of Chlorinated Volatile Organic Compounds (U)

Prepared by Savannah River Technology Center Environmental Sciences Section

T.R. Jarosch, J.S. Haselow, J. Rossabi, S.A. Burdick, R. Raymond, J.E. Young, K.H. Lombard

Authenticated by:

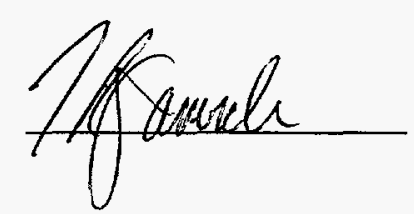

Prepared for the U.S. Department of Energy under Contract No. DE-AC09-89SR 18035

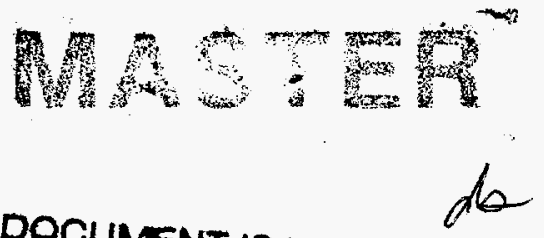

OISTRIBUTION OF THIS DOCUMENT IS UNLIMITED 


\section{CONTENTS}

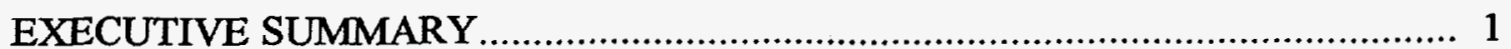

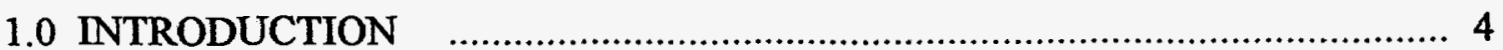

1.1 Technologies Selected for Testing....................................................... 4

1.2 Destruction versus Conversion............................................................... 5

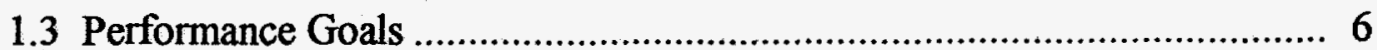

2.0 EXISTING "BASELINE" TECHNOLOGIES .......................................... 8

2.1 Activated Carbon Adsorption .............................................................. 8

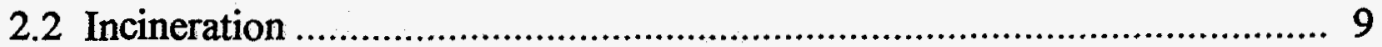

2.3 Thermal Catalytic Oxidation ................................................................. 9

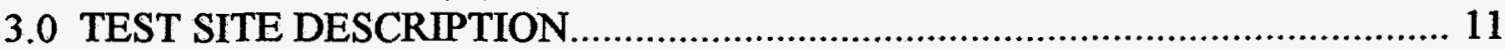

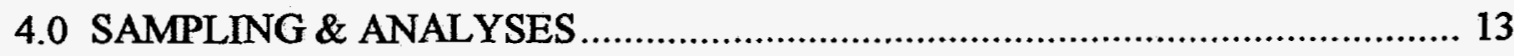

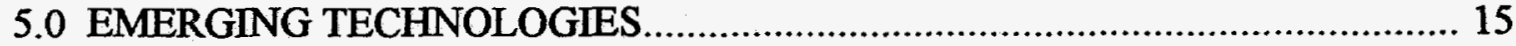

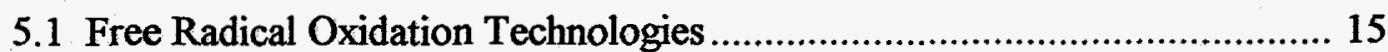

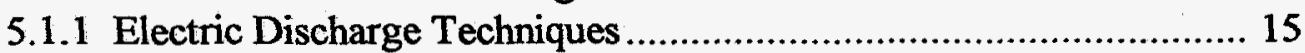

5.1.1.1 High-Energy Corona ......................................................... 16

5.1.1.2 Cold Plasma ..................................................................... 16

5.1.2 Photocatalytic Oxidation.............................................................. 17

5.1.3 Vapor-Phase Photolytic Destruction .......................................... 18

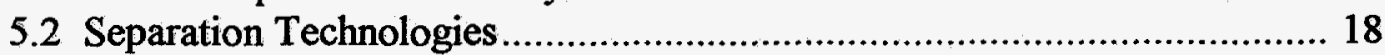

5.2.1 Regenerative Adsorption and Solvent Recycling ……..................... 18

5.2.2 Gas-Phase Membrane Separation................................................ 19

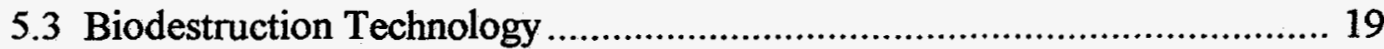

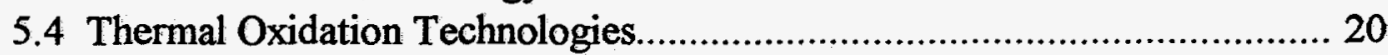

5.4.1 Carbon Regeneration by Steam Reforming..................................... 20

5.4.2 Pulsed Combustion................................................................... 20

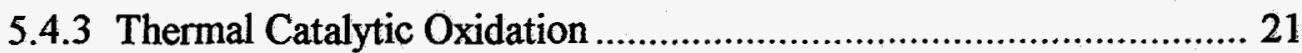

6.0 RESULTS AND DISCUSSION OF TECHNOLOGIES TESTED ..................... 22

6.1 Free Radical Oxidation Technologies ...................................................... 22

6.1.1 Vapor-Phase Photolytic Destruction ............................................... 22

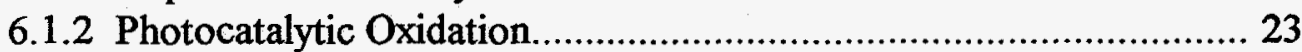

6.1.2.1 University of Wisconsin ...................................................... 23

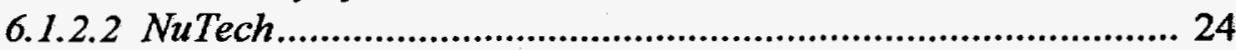

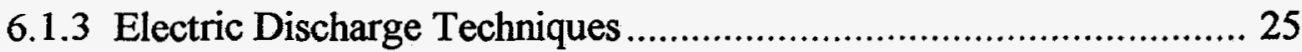

6.1.3.1 High-Energy Corona ............................................................ 25

6.1.3.2 Cold Plasma .......................................................................... 26

6.1.4 Ozone Enhanced Oxidation........................................................ 27

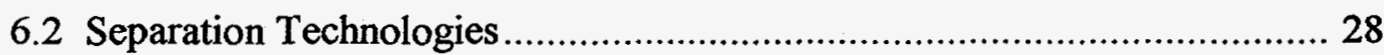

6.2.1 Regenerative Adsorption and Solvent Recycling ……................... 28

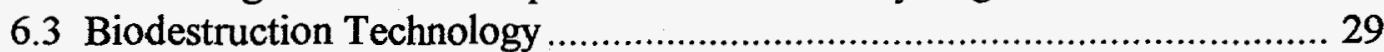

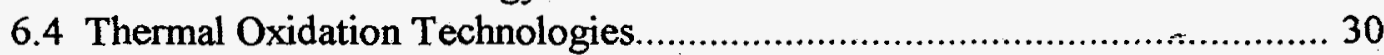

6.4.1 Carbon Regeneration by Steam Reforming................................... 30

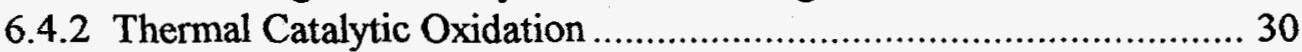

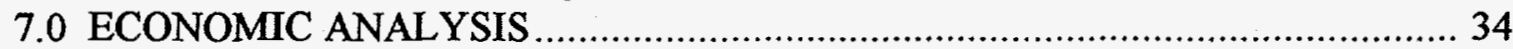


7.1 Introduction

7.2 Baseline Tehnology: Thermal Catalytic Oxidation .................................... 35

7.3 Comparison of Energy Requirements .................................................... 35

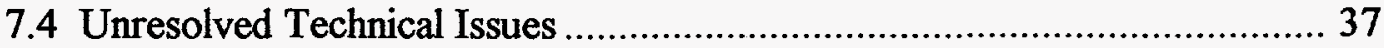

8.0 SUMMARY

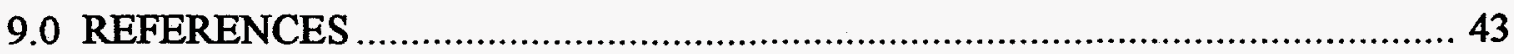

APPENDIX

\section{LIST OF TABLES}

Table Page

6.1 Summary of Results from University of Wisconsin Photocatlytic Oxidation Test....31

6.2 Summary of Results from NuTech Photocatalytic Oxidation Test ............................31

6.3 Summary of Results from High-Energy Corona Destruction Test ............................32

6.4 Summary of Results from Cold Plasma Destruction Test ........................................32

6.5 Summary of Results from Enhanced Ozone Oxidation Test ...................................33

6.6 Summary of Results from Thermal Catalytic Oxidation Test Johnson-Matthey

Catalyst

7.1 Summary of Energy Requirements and Capital Costs for VNID Catalytic Oxidation Units .39

7.2 Estimate of Total Operating Cost for ISH Thermal Catalytic Oxidation Unit..........39

7.3 Comparison of Energy Requirements for Demonstrated Technologies ...................40

\section{LIST OF FIGURES}

Figure

3.1 Schematic of Soil Vapor Extraction (SVE) Unit 


\section{EXECUTIVE SUMMARY}

Chlorinated volatile organic compounds (CVOCs) are the most pervasive subsurface contaminants within the Department of Energy Complex. The most prevalent remediation technologies for CVOCs ultimately produce a gas-phase stream containing CVOCs, either via soil venting from the unsaturated zone or ground water recovery from the saturated zone and subsequent airstripping. Many states, including South Carolina, have permitted the direct discharge of the gaseous CVOCs to the atmosphere, where these compounds are decomposed through ultraviolet photolysis. However, the 1990 Clean Air Act (CAA) Amendments will require that these emissions be abated through the best available technologies. Because of the ubiquity of subsurface CVOC contamination, a modest improvement can provide tremendous benefits over the currently utilized technologies of incineration, catalytic oxidation, and carbon adsorption. This need has motivated the development of diverse technologies for abatement of CVOC emission which may be classified as: free radical oxidation, thermal oxidation, separation/recovery, and biodestruction technologies. The Savannah River Technology Center has field tested and evaluated several technologies from each of these classes under the VOC's in Non-Arid Soils Integrated Demonstration (VNID) that was funded by the D.O.E. Office of Technology Development (OTD).

The demonstrations were conducted with a soil vapor extraction system connected to a vertical well screened in the vadose zone. The site is contaminated with chlorinated organic solvents used as degreasing agents in the reactor materials facility. The primary soil contaminants at the SRS are perchloroethylene (PCE), trichloroethylene (TCE), and 1,1,1-trichloroethane (TCA). The total CVOC concentration at the test site could exceed $10,000 \mathrm{ppm}(\mathrm{v} / \mathrm{v})$ with a typical composition range of $85-90 \%$ PCE, 10-12\% TCE, and 1-2\% TCA. The well off-gas was typically diluted to lower the maximum concentrations down to a few thousand ppm. While the extraction system was capable of flow rates up to $500 \mathrm{scfm}$, flow rates used in the demonstrations varied from 0.1 to $100 \mathrm{scfm}$.

All of the technologies tested at the SRS proved or exhibited strong potential as viable methods for treating off-gas streams containing chlorinated organics. Most are applicable to moderate flow rate streams (typically less than one thousand $\mathrm{cfm}$ ) with concentrations ranging from 50 to 3000 ppmv. These conditions are typical for soil vapor extraction applications. It should be noted that these technologies are also applicable to non-chlorinated VOC's (e.g. BTEX's). Each technolgoy varies in its stage of development towards complete commercialization. Most of the tests conducted under this program were of a very short and periodic nature. Future testing efforts should focus on fewer technologies with more extended continuous operation. A testing program of this nature is especially critical for the emerging technologies that must prove their reliability under such conditions to be deemed ready for commercialization. Most of the technologies tested involved innovative destruction techniques. All of these destruction techniques, except thermal catalytic oxidation and biodestruction, produce by-products that are more hazardous than the targetted chlorinated compounds. This finding revealed a need for improved sampling techniques to identify and quantify all potential by-products produced in the 
destruction technologies. In addition, acid scrubbing equipment for abatement of hydrochloric acid (a desired product but also on the new air toxics list in the 1990 CAA Ammendment) must be considered for full-scale applications of the destruction technologies.

The free-radical oxidation processes are relatively immature in their development process. Early results are encouraging though as they can potentially require less energy and/or offer concentration dependent energy use relative to thermal techniques. This can be especially critical to remediation applications where concentrations will vary significantly with time. In addition, all of the methods appeared to offer greater CVOC conversion than thermal processes (typically greater than $99 \%$ ) and exhibited a characteristic trend in ease of destruction: TCE $\gg$ PCE $>$ TCA. A primary unresolved technical issue involves the formation of chorinated side products including phosgene, chloroacetic acids, chloroform, carbon tetrachloride, pentachloroethane, and hexachloroethane. These incomplete decomposition products are more regulated, toxic, and typically more refractory towards further oxidation. This issue must be solved before these processes can be commercially viable and publicly acceptable.

The thermal catalytic processes are encouraging. When the optimum space velocity and temperature are used, destructions greater than ninety-nine percent were achieved for PCE, TCE, and TCA (the ease of destruction for thermal techniques are somewhat reversed vs free radical techniques with TCA $>$ TCE $>$ PCE). There are slightly detectable amounts of incomplete conversion products but none have been detected with the VNID's operable units. This technique, however, becomes energy intensive as CVOC concentrations drop below 100 ppmv. This process will meet the requirements of the Clean Air Act Amendments and will ostensibly be more favorable than activated carbon or incineration. Many sites, including the SRS, are choosing thermal catalytic oxidation for controlling emissions for the soil venting of CVOCs.

The separation processes are good for recovering liquid phase CVOCs. This technology is especially applicable to lower concentration streams (e.g. in the latter stages of remediation where mass transfer limitations cause a drop off in removal rates). There are still technical problems associated with the co-collection of water, limited adsorbent lifetimes, autocatalytic oxidation reactions (with activated carbon systems), and potential breakdown of the organics during regeneration. The first three issues can be reduced with the use of new synthetic adsorbents. The primary unresolved issue, however, is not technical and involves the liability and cost associated with handling the CVOCs for recycling. Under current law, the liquid CVOC recovered in remediation of a waste site is considered hazardous waste until an entity purchases the solvent for reuse. Until it is resold, the generator is responsible for proper handling and storage of the waste/product. Current regulations also require additional permitting if the "product" must be reclaimed further prior to reuse (dewatered, distilled, etc.). Furthermore, while there is a present market for recovered chlorinated organics, long term remediation schemes are gambling on a continued favorable market as well as a stable regulatory environment. Due to the presence of several hidden costs involved with these nontechnical issues, this technology may not be economically favored but is easily the "greenest" solution when consideration of reduced emissions of carbon dioxide and hydrochloric acid are given or an account of the energy saved versus production of virgin solvents is made. 
Biodestruction technologies may provide a means of reducing the load on other treatment systems but are generally better suited for aqueous waste treatment. The technolgy tested at the SRS involved the transfer of TCE from the vapor phase to water, a clearly thermodynamically unfavorable process given the Henry's constants and water solubilities of chlorinated compounds. This limitation, combined with the slower reaction rates for biodestruction would inadversely affect scale-up of this technology. Alternative biotreatment techniques (e.g. filtration) which "mimic" the carbon adsorption/regeneration semi-batch concept are probably more applicable to off-gas streams. 


\subsection{INTRODUCTION}

The purpose of this report is to summarize the results of the program for off-gas treatment of atmospheric emissions of chlorinated volatile organic compounds (CVOCs), in particular trichloroethylene (TCE) and perchloroethylene (PCE). This program was funded through the Department of Energy Office of Technology Development's VOC's in Non-Arid Soils Integrated Demonstration (VNID). The off-gas treatment program was initiated after testing of in-situ air stripping with horizontal wells was completed (Looney et al., 1991). That successful test expectedly produced atmospheric emissions of CVOCs that were unabated. It was decided after that test that an off-gas treatment program would complement the Integrated Demonstration not only because off-gas treatment is an integral portion of remediation of CVOC contamination in groundwater and soil but also because several technologies were being developed across the United States to mitigate CVOC emissions. A single platform for testing off-gas treatment technologies would facilitate cost effective evaluation of the emerging technologies.

Another motivation for the program is that many CVOCs will be regulated under the Clean Air Act Amendments of 1990 and are already regulated by many state regulatory programs. Additionally, compounds such as TCE and PCE are pervasive subsurface environmental contaminants, and, as a result, a small improvement in terms of abatement efficiency or cost will significantly reduce CVOC discharges to the environment as well as costs to United States government and industry.

\subsection{Technologies Selected for Testing}

The main emphasis of this program is on technologies that are being developed in the DOE Complex and by industry teaming with a DOE partner. The participants within the DOE Complex were selected by two separate calls for proposals and reviews. The technologies were selected for demonstration on the basis of technical merit, the ability of the technology to treat contaminants on-site without generating secondary waste, and to represent as wide a variety of technologies as is possible. Two solicitations for proposals were made. The technologies that were selected from the first solicitation, followed in parentheses by the DOE site and the industrial partner, were: activated carbon regeneration by steam reforming (Sandia National Laboratory [SNL] and Synthetica Technologies, Inc.), gas-phase bioreactor (Savannah River Technology Center and Ecova Corp.), membrane separation (Westinghouse Hanford Co. and Membrane Technology Research, Inc.), and high-energy corona (Battelle Pacific Northwest Laboratory), and from the second solicitation: silent discharge plasma (Los Alamos National Laboratory), xenon flashlamps (Argonne National Laboratory and Purus, Inc.), and pulsed combustion (SNL). Additionally, there was substantial interest in attempting to recover the solvents in the soil for recycling so a system incorporating thermal desorption of activated carbon and condensation recycle process was also selected for testing in cooperation with Idaho National Engineering Laboratory (INEL), NUCON International, Inc., Science Application International Corporation (SAIC), and 3M, Inc. 
Following the technology selection process, the off-gas testing program received new guidance, and as a result, a decision was made to test the membrane separation technology at the Hanford site with a carbon tetrachloride contaminated air stream. Additionally, funding for the gas-phase bioreactor was shifted from OTD funds to internal WSRC funding while funding for the pulse combustion test was discontinued.

From the beginning, it was recognized that the off-gas testing site might not be fully utilized; therefore, an advertisement was placed in the Business Commerce Daily to solicit other institutions that would be interested in using the test site but with the provision that no direct compensation would be provided. Indirect compensation via the utilities, free use of the test site, and sample analyses are provided at no cost as long as the company is willing to share the data. Through this avenue, NuTech Environmental (a Division of NuTech Energy Systems) and the University of Wisconsin were identified to test their photocatalytic oxidation systems; Johnson Matthey Inc. for their thermal oxidation catalyst, and Ultrox Inc. for their enhanced ozone oxidation process.

\subsection{Destruction versus Conversion}

Destruction is defined herein as the complete mineralization of CVOCs to carbon dioxide and hydrochloric acid $(\mathrm{HCl})$. Conversion is defined herein as the transformation of the carbon in the inlet CVOC to another product, either carbon dioxide or another organic or inorganic compound. For example, if a gas concentration is 1000 parts PCE on the inlet side of a treatment process and less than 5 parts on the outlet, that would represent greater than 99.5 percent conversion, but would not say anything about percent destruction. If the outlet side had for example 500 parts hexachloroethane and no other organic compounds, then the destruction would only be 50 percent.

A dilemma exists regarding the calculation of conversion and destruction. For example, there are (at least) stoichiometrically three reactions that can result in complete oxidation of PCE on a carbon basis:

$$
\begin{aligned}
& \mathrm{C}_{2} \mathrm{Cl}_{4}+2 \mathrm{H}_{2} \mathrm{O}+\mathrm{O}_{2} \Leftrightarrow 2 \mathrm{CO}_{2}+4 \mathrm{HCl} \\
& \text { or } \\
& \mathrm{C}_{2} \mathrm{Cl}_{4}+\mathrm{H}_{2} \mathrm{O}+1.5 \mathrm{O}_{2} \Leftrightarrow 2 \mathrm{CO}_{2}+2 \mathrm{HCl}+\mathrm{Cl}_{2} \\
& \text { or } \\
& \mathrm{C}_{2} \mathrm{Cl}_{4}+0_{2} \Leftrightarrow 2 \mathrm{COCl}_{2}
\end{aligned}
$$

The PCE is completely mineralized in the first reaction only (although some may argue that $\mathrm{COCl}_{2}$ or phosgene is a completely "mineralized" product). Thus, conversion estimates based on $\mathrm{HCl}$ outlet concentrations are tenuous at best. Added to this problem, is that often times many 
other incomplete organic destruction products are formed such as carbon tetrachloride, chloroform, pentachloroethane and hexachloroethane from PCE. When these more highly chlorinated compounds are produced, from a stoichiometric and mechanistic argument, chlorine may also be produced. Thus, for convenience and for a matter of comparison, percent destruction is the percent of organic carbon that is completely oxidized, and percent conversion is the percentage of inlet contaminant that does not appear on the outlet side. Due to the limited scope and funding of this testing program, sampling and analytical techniques that would allow for complete identification of all compounds and provide both carbon and chlorine material balances were not used. The primary analytical tool employed, a gas chromatograph with a flame ionization and electron capture detector, allowed us to determine CVOC conversions and identify those stable organic intermediates formed in the various processes. Unstable species, especially when at high concentrations, were observed but not quantified.

While discussing stoichiometry, it is important to note that water is a reactant and not a product in the complete mineralization of the more highly chlorinated CVOC's. In fact, as is evident in the reactions listed above, as the availability of water as a reactant decreases, oxidation can produce more harmful products including chlorine gas and phosgene. However, as will be discussed later, there are technologies in which water retards "destruction" efficiencies and/or increases energy requirements. The role of water in any given off-gas technology is an important issue for soil venting applications where moisture levels can vary widely and humidity control can affect economics and/or lead to the production of a secondary waste stream.

\subsection{Performance Goals}

A continuing theme of the OTD program is "better, faster, cheaper, safer" as compared to existing technologies. Faster does not necessarily apply to off-gas treatment because it is limited by removal rates. Although, at highly contaminated sites, technologies which can handle higher concentrations, can potentially reduce remediation time schedules. The existing technologies, which are discussed below, set the standards for comparison regarding better and cheaper. Caution must be exercised when making direct comparisons to existing technologies, however, because some technologies are better suited for different process conditions. For example, granular activated carbon (GAC) in fifty-five gallon drums is probably not the appropriate existing technology for comparison if the gas stream contaminant mass flux will be greater than 100 pounds per day.

Given that the technology must have some advantages over existing technologies, there are also regulatory driven performance standards that must be met. The performance standards for abatement of new and existing sources are confuising at best, especially when compared to incineration performance standards which essentially state that an incineration facility must attain 99.99 destruction removal efficiency for each principal organic hazardous constituent (40 CFR 264.343). Incineration regulations were not intended for other abatement technologies and thus these technologies are subject to the Clean Air Act as amended in 1990 (CAA) and described in Federal Law 71, Section 112. 
The CAA performance standards for abatement of particular compounds (i.e. the new air toxics list of 189 hazardous air pollutants which include TCE, PCE, and hydrochloric acid) are poorly defined and subject to interpretation of the "administrator" which in South Carolina would be EPA Region IV or the South Carolina Department of Health and Environmental Control (SCDHEC). For example, the CAA states that "sources of hazardous air pollutants shall require the maximum degree of reduction in emissions ... taking into consideration the cost of achieving such emission reduction...". The maximum degree of reduction is defined in two ways: 1) "the average emission limitation achieved by the best performing [process on] twelve percent of the existing sources..." Or essentially, take all the existing or recent sources that are being controlled and take the average percent reduction in emission of the top one-eighth of the performers, or 2) "the average emission limitation achieved by the best performing 5 sources..." As interpreted, the same process could be the best performing on five sources and the average effectiveness of that process would define the performance standard. These standards comprise what is termed the Maximum Achievable Control Technology or MACT. There are of course time periods that must be considered and other interpretations that must be made of the law, but the final interpretation of the law is the responsibility of the administrator of the law, which is typically a state regulator. For the purposes of this testing program, the air permit, granted by the SCDHEC, assumed a $95 \%$ removal efficiency for the principal chlorinated solvents (this is actually $5 \%$ above the anticipated requirement of $90 \%$ reduction). In addition, due to the relatively small scale and limited time schedule for these tests, the $\mathrm{HCl}$ emissions were expected to be low enough so as not to require any acid scrubbing equipment (the current permitted hourly average emission rate for $\mathrm{HCl}$ is 4 $\mathrm{lb} / \mathrm{hr}$ ). 


\subsection{EXISTING "BASELINE" TECHNOLOGIES}

Currently utilized technologies for abating CVOC emissions are activated carbon adsorption and thermal processes including incineration and catalytic oxidation (Rinko and Traester, 1988; Buck and Seider, 1991; Adams and Clark, 1991). Each of these methods are useful for a certain range of process variables, i.e. flow rate, contaminant concentration, expected life of operation, etc. Some of the strengths and weaknesses of each of these available technologies are discussed below.

\subsection{Activated Carbon Adsorption}

Activated carbon adsorption is a simple process that is best suited for low mas flow-rates. Higher mass flow rates can mandate the use of unmanageable amounts of carbon. The carbon's adsorption capacity, however, is concentration dependent (maximum equilibrium loadings are proportional to the vapor concentrations) and can vary from a few percent to near or greater than fifty percent by weight. When opting for activated carbon, one must choose between using the carbon once, having it regenerated and/or reactivated for re-use off-site, or investing in the regenerating equipment. Due to the added capital costs, the latter option is typically used only at large sites or for use as an emissions abatement system at industrial plants where large volumes of solvent can be recovered for reuse. Of course, without regeneration, it is simply a transfer of CVOC from one phase to another. For the proper conditions, the advantages of activated carbon are that it has extremely low capital and operating costs, and the system is easy to set-up and operate. Often, the use of 55 gallons drums of carbon may be suitable. The cost of carbon adsorption can vary greatly depending primarily on regulatory requirements and regeneration costs (virgin carbon cost are a small fraction of the actual total costs). Typical costs quoted range from $\$ 10$ to $\$ 75 / \mathrm{kg}$ with the lower costs associated with moderate concentrations and on-site regeneration. Some of the disadvantages, depending upon whether regeneration is used, are: 1) It isn't economical for large mass flow rates; 2) There is a limited regeneration lifetime (typically 5 to 10 cycles), so that ultimately one must deal with unregenerable carbon that may be subject to land disposal restrictions; 3 ) There is shipping, handling and liability associated with regenerating the carbon; 4) There may be additional sampling and analysis requirements for the spent carbon; 5) A heat exchanger may be necessary to operate on a favorable adsorption isotherm (lower temperature) or at a lower relative humidity, 6) activated carbon is subject to auto catalytic oxidation reactions (fires) that can be stimulated by the heat of adsorption, and 7) water competes for adsorption sites which limits the capacity of the carbon (e.g. Gong and Keener, 1993). Onsite regeneration can remove or reduce some of these disadvantages. This fact, combined with the ability to lease regeneration equipment and/or services, can make this technique more enticing for use at smaller sites. This is especially true if provisions are in place for beneficial reuse of the solvents and regulators allow the recovered solvents to be treated as product.

GAC can be regenerated or reactivated by thermally desorbing the solvents. Some established thermal methods for reactivating spent carbon, typically conducted at temepratures ranging from 
500 to $1000^{\circ} \mathrm{C}$, are infrared heating, incineration or catalysis (Koffskey and Lykins, 1990; Adams and Clark, 1991). Regeneration can involve destruction or recovery of the adsorbed solvents. Recovery methods typically use a heated inert gas to desorb the solvents at temperatures typically below $300^{\circ} \mathrm{C}$. Steam is also used, although more often in off-gas destruction methods, as it introduces a secondary waste and enhances the potential formation of $\mathrm{HCl}$ (it can also increase the loss of carbon with each regeneration cycle). The concentrated vapor stream exiting the bed during desorption is run through a refrigeration cycle to condense out the solvent vapors. There are a number of technologies commercially available for solvent adsorption and recovery. Engineering efforts in this area are focused either on improving the adsorption efficiency/selectivity (i.e. synthetic adsorbents) or on improving the refrigeration cycle efficiency (Basta, 1991, GE Research \& Developemnet Center, 1994).

\subsection{Incineration}

Incineration, or high-temperature oxidation is a simple technology best suited for streams with relatively high flow-rates and concentrations of CVOC's (see Dempsey and Oppelt, 1993 for a review of incineration technology). Due to the high energy demands (temperatures $\sim 900^{\circ} \mathrm{C}$ ) and low heating value of most CVOC's, incineration requires an auxiliary fuel source which will also increases the emission of carbon dioxide. Total costs for incineration are approximately $\$ 2$ to $\$ 6$ per kilogram of CVOC and destruction efficiencies of greater than 99.99 percent can be routinely achieved. Incineration of CVOC's can produce chlorinated products of incomplete combustion (PICS), such as dioxin, and will produce nitrogen oxides. However, the release of these by-products has been successfully controlled in bench scale studies using ammonia injection (Takacs and Moilanen, 1991). One of the main barriers in the use of incinerators for treating waste is public objection. Despite the large amount of technical data available indicating the advantages of incineration over many other methods with respect to destruction efficiency, safety, and cost, the general public adheres to a "not in my backyard" position when a site selection process is initiated. This position is strengthened by the public's increased awareness of environmental issues and some highly publicized environmental catastrophes (Steverson, 1991).

\subsection{Thermal Catalytic Oxidation}

Although still considered as an emerging technology in certain respects, catalytic oxidation has developed into an abatement method for CVOC emissions. While catalytic oxidation is a thermal process, it is not usually viewed as incineration, provided there is not an open flame. Catalysis has lower energy demands than incineration and is better suited for waste streams that have moderate concentrations of CVOCs (Palazzolo et al., 1986; Herbert, 1990; Frost et al., 1991). Destruction efficiencies of greater than $95 \%$ have been achieved. This process previously required frequent recycling or regeneration of the catalyst, because of irreversible chlorine poisoning of the noble metals (Kittrell et al., 1991); however, a proprietary metal catalyst has been developed and utilized which is not subject to poisoning, yet maintains a high conversion efficiency (Kittrell et $a l ., 1991$ ). Current catalysts are still subject to poisoning by other elements (including sulfur and phosphorous), and are subject to metal sintering, masking, and fouling, all of which reduce the available active metal surface area. As with incineration, treatment of the off-streams from the catalytic process may require neutralization of the hydrochloric acid that is generated. 
Additionally, this technology has significant energy requirements, but not as much as incineration because maximum operating temperatures are approximately $450-500{ }^{\circ} \mathrm{C}$ (versus $900{ }^{\circ} \mathrm{C}$ for incineration). For both thermal technologies, however, energy costs can be reduced significantly with the use of heat recovery exchangers or regenerative heat recovery systems (van der Vaart, et al 1991a and 1991b). Although, these energy recovery techniques will carry associated increases in capital equipment costs. Costs for the destruction of CVOCs with catalysis are comparable to incineration, but catalysis has potentially better regulatory acceptance.

Many of the new destruction technologies make claims of greatly reduced energy costs over thermal methods. This is true in many cases as will be discussed in ensuing sections. It is appropriate, here, to provide a baseline energy requirement for a typical catalytic unit operating in the flow range of these tests. The energy requirement to heat an air stream (5\% moisture by volume) from 20 to $450^{\circ} \mathrm{C}$ is $15.2 \mathrm{~kJ} / \mathrm{ft}^{3}(537 \mathrm{~J} /$, or a power consumption of $25.3 \mathrm{~kW}$ per 100 $\mathrm{scfm}$; note that approximately $10 \%$ of this energy will actually be provided by gas compression in the blower used in soil venting). For a normal unit operating with a heating efficiency of $90 \%$ and a recuperative heat exchanger with a $40 \%$ energy recovery, the energy requirement is $10.1 \mathrm{~kJ} / \mathrm{ft}^{3}$ ( $360 \mathrm{~J} /$, or a power consumption of $16.9 \mathrm{~kW}$ per $100 \mathrm{scfm}$ ). This energy consumption, however, is independent of the contaminant concentration over the normal applicable range for thermal catalysis (approximately 50 to $3000 \mathrm{ppmv}$ ), therefore, the energy consumption per kg of contaminant destroyed can vary significantly (from 10 's to 100 's of $\mathrm{kW}-\mathrm{hr} / \mathrm{kg}$ ). This is an important factor, especially in soil venting applications, where initial concentrations may be high and drop off dramatically to some asymptotic limit over time. As a result, a major advantage to alternative destruction technologies resides not only in the absolute difference in energy requirements, but also in their ability to vary energy use with contaminant type and concentration. 


\subsection{TEST SITE DESCRIPTION}

The test site was near the A-014 outfall at the Savannah River Site (SRS) that previously received discharges which contained trichloroethane (TCA), TCE, and PCE (Marine and Bledsoe, 1984). As a result, the soil in the area contains these CVOCs (CH2M Hill, 1990). A soil venting well was installed in the vadose zone at this area and screened from 55 to 115 feet below surface. The water table is approximately 116 feet below surface at the site. A vacuum blower is connected to the well which supplies contaminated air to the processes that are being tested (see Figure 3.1). The contaminated air is passed through a cyclone separator and a filter to remove water and particulates before the gas flows through the treatment process. Activated carbon is used on the end of the system to polish the contaminated stream or serve as a backup in case of a system failure. All processes are connected on the positive pressure side of the vacuum blower so that the $\mathrm{HCl}$ generated by the treatment process will not come in contact with the vacuum blower system. There are, however, benefits in reduced fugitive emissions by operating on the vacuum side. In addition, as will be discussed further, certain technologies are better suited for operation under a mild vacuum.

The blower can generate a maximum of 11 inches of mercury vacuum on the well and can safely maintain discharge pressures as great as 5 psig. The vacuum blower has a variable speed drive and the discharge can be passed through a manifold so that flow rates from 5 to $300 \mathrm{scfm}$ can be supplied. However, lower flow rate systems ( $<5 \mathrm{scfm})$ were typically operated with separate pumps (oil-less carbon vane or metal bellows pumps).

Analyzed contaminant concentrations were as great as 16,000 part per million by volume (ppmv), for PCE, 3,000 ppmv for TCE, and 500 ppmv for TCA. Additionally, trace but detectable amounts of 1,1-dichloroethylene have been detected. An air dilution valve is located on the vacuum side of the blower so that these concentrations can easily be reduced. Obviously though, the concentrations are variable, being dependent upon the time the vacuum blower has been running, atmospheric pressure, vacuum levels, etc. The air removed through the well is saturated with water at approximately $16^{\circ} \mathrm{C}$ and is in thermal equilibrium with the soil. The temperature of the contaminated air increases as it passes through the blower to as much as $65^{\circ} \mathrm{C}$, depending on the ambient air temperature, vacuum levels, and the pressure differential across the vacuum blower. 


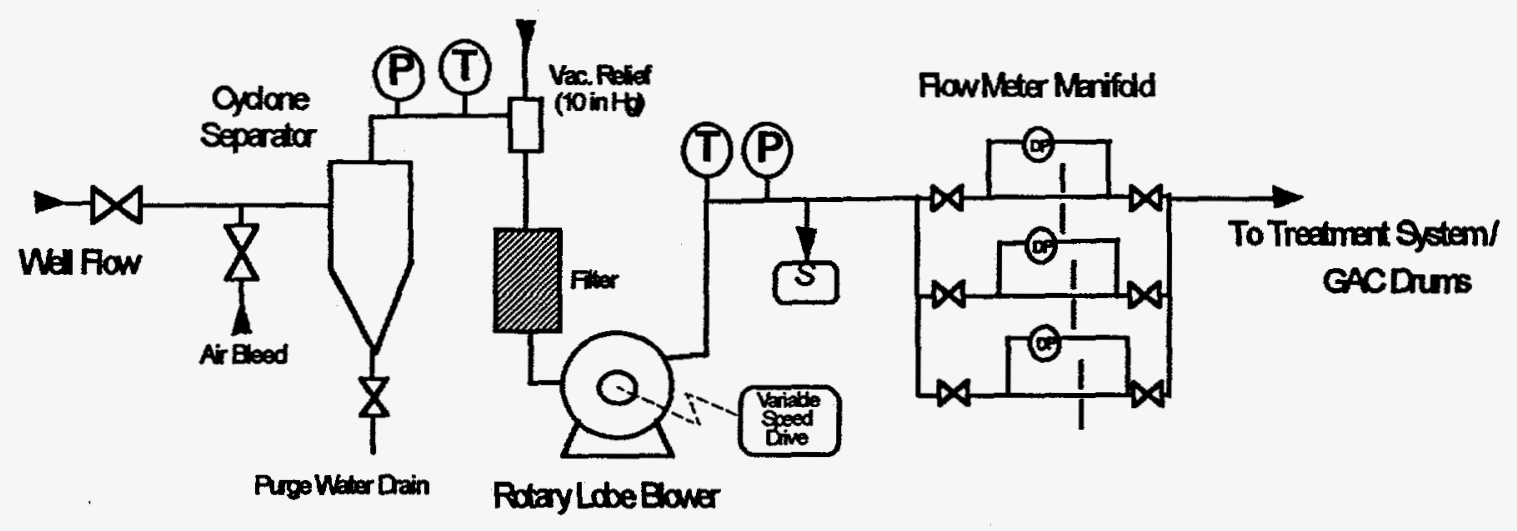

(B) Pressuretemperature

(5) SamplePort

Figure 3.1 Schematic of Soil Vapor Extraction (SVE) Unit 


\subsection{SAMPLING \& ANALYSES}

Gas phase samples were collected into 1 liter Tedlar $^{\mathrm{TM}}$ sampling bags (Analytical Testing Corporation, PA) on both the inlet and outlet side of the process being tested. The samples were stored in a cool dark location and analyzed within four hours after being taken. Outlet samples were typically analyzed within one hour to ensure that the integrity of the sample was not significantly compromised with time because of decomposition of the contaminants of concern and absorption onto the sampling bag (e.g. Johnson, 1985). Despite these limitations, the samples are believed to be representative. For comparison, during a test of Ultrox's process, an outlet sample was taken with a sampling bag at approximately the same time that an on-line IR analyzer was used. The bagged sample was analyzed with a GC, and both the IR and the GC analyses indicated that the PCE contaminant concentration was approximately $28 \mathrm{ppmv}$. Additionally, during the test of the High-Energy Corona process, Battelle-PNL researchers had an on-line gas chromatograph for process monitoring. Samples were again taken with bags and analyzed on the $\mathrm{GC}$ and they were within five percent of those analyzed using the on-line GC.

The gas chromatograph used for analysis is an HP 5890 Series II. The critical characteristics and operating conditions for the $\mathrm{GC}$ are listed below:

Column: $\quad$ VOCOL (SUPELCO) wide bore glass capillary $60 \mathrm{~m} \times 0.75 \mathrm{~mm} \mathrm{ID}, 1.5 \mu \mathrm{m}$ film

Sample Volume: $\quad 300 \mu \mathrm{l}$ (manual syringe injection) (1000 $\mu$ l Hamilton Gas-Tight syringe)

Oven Temp. $\quad 40^{\circ} \mathrm{C}$ for 2 minutes, ramp at $10^{\circ} \mathrm{C} / \mathrm{min}$. to $185^{\circ} \mathrm{C}$, hold 5 minutes

Program: (for effluent samples: ramp to $215^{\circ} \mathrm{C}$ and hold for 10 minutes)

Split Ratio $\quad 10: 1$

Column Flow: $\quad 8 \mathrm{cc} / \mathrm{min}$.

Detectors $\quad$ FID/ECD (10:1 splitter)

Detection Limit*: $\quad 0.5$ ppm (PCE and TCE)

Integrator: $\quad$ HP 3396A

(* Based on minimum standard of $1 \mathrm{ppmv}$; Actual integratable concentrations of $0.05 \mathrm{ppmv}$ PCE and $0.2 \mathrm{ppmv}$ of TCE and TCA)

The inlet gas samples were typically analyzed with the FID, because the ECD would be overwhelmed by the higher concentrations ( $500 \mathrm{ppmv}$ and greater). The outlet samples were 
typically analyzed on the same GC with an ECD, because the ECD is significantly more sensitive to chlorinated (electronegative) compounds than the FID and thus has a lower detection level.

The GC is calibrated with commercial standards of $1,10,100$, and 1000 ppmv (nitrogen balance) of the compounds of interest. The lower concentration gases were used to calibrate the ECD while the higher concentrations were used to calibrate the FID. Due to the broad range of concentrations encountered during the tests and the likelihood of enhanced errors introduced by gas dilution methods, concentrations were calculated by interpolation rather than linear regression; i.e. an average linear response was assumed between standards. Calibration standards were always analyzed at least once daily and usually more frequently so that the stability of the GC could be monitored. In addition, the standards were handled in a manner similar to the samples; i.e. the standards were collected and stored in Tedlar bags and analyzed periodically (typically two to three times) over a period of up to 6 to 8 hours. Calibrations were based on the average response of both "fresh" and "aged" standards. The effect of hold time on the response (area counts/concentration) of standards shows a small $(\sim 0.1 \% / \mathrm{hr})$ but statistically significant drop over periods up to 10 hours. The cumulative coefficient of variation for the response (area counts/concentration in ppm) of the standards ranges from .04 to .07 . For these reasons, the calculated concentrations of inlet samples were believed to be very representative, although the presence of water vapor and oxygen in the samples could affect detector response and/or increase degradation and promote adsorption onto the bag.

Approximately 10 percent of the samples collected were analyzed with gas chromatography mass spectrometry (GC/MS) using a modified version of EPA SW-846 method 8260A. Samples were concentrated using a OI Analytical model 4460A Dynamic Headspace concentrator (purge and trap), using a three stage (10 cm Carbopack $B^{\mathrm{TM}} / 6 \mathrm{~cm}$ Carboxen $1000^{\mathrm{TM}} / 1 \mathrm{~cm}$ Carboxen $1001^{\text {TM }}$ ) trap. Separation was performed with a Hewlett Packard 5890 series II gas chromatograph on a $30 \mathrm{~m} \times 0.53 \mathrm{~mm}$ VOCOL ${ }^{\mathrm{TM}}$ fused silica capillary column with $3 \mathrm{um}$ film thickness. Identification and quatitation was performed with a Hewlett Packard model 5971 quadrupole mass spectrometer. The GC/MS analyses was used to identify unknown compounds in the gas samples, which is of particular importance for the post-process side. The GC/MS provides an order of magnitude estimate of the concentration of the secondary analytes because the GC/MS is not calibrated (nor are calibration standards readily available) for many of the decomposition products that are observed for TCE and PCE. Estimated concentrations are made further suspect by the potential for significant degradation of reactive intermediates prior to analysis or within the purge and trap unit used with the analytical method. 


\subsection{EMERGING TECHNOLOGIES}

The emerging technologies for abatement of CVOC emission can be classified as: free radical oxidation, separation/recovery, biodestruction, and thermal oxidation technologies. Each of these methods have strengths and weaknesses that are summarized below. Rossabi et al., 1991 and Haselow et al., 1992 also provide a review of emerging technologies for off-gas treatment.

\subsection{Free Radical Oxidation Technologies}

Free-radical oxidation refers to technologies that utilize some energy source to create reactive free radicals which act as oxidizing species or which can be easily oxidized or reformed to simpler products. These techniques also fall under a more commonly defined research field known as advanced oxidation technologies or processes (AOT's or AOP's). Free radicals can be created by bombarding a molecule with electrons created in beams or discharges or by exciting electron bonds with some form of energy, such as high-frequency light or $x$-rays. Included in this category, are techniques that employ ozone, which is typically produced with non-thermal plasma (electrical discharge) generators, and photocatalytic techniques in which UV light is used to generate radicals at the gas-solid (semi-conductor) interface. With free radical oxidation of CVOCs in a humid air stream, the hydroxyl and atomic oxygen radicals, both strong oxidizing agents, are formed. In addition, carbon-chlorine bonds and carbon-carbon bonds can be cleaved to form free radicals if the incident energy or electric field is sufficient or via dissociative electron attachment reactions in discharges or beams. It is the goal of the free-radical oxidation process to have the free-radicals recombine to form $\mathrm{HCl}$ and carbon dioxide. A draw back to the free radical techniques are the myriad of potential reaction pathways which can result. The free radicals that are created from the CVOCs often recombine to form more toxic compounds, some of which, depending on the energy source, are more difficult to mineralize than the original CVOC. There is currently a great deal of work focused on the predominant mechanism(s) involved with the oxidation of CVOC's (1st International Conference on Advanced Oxidation Technologies for Water and Air Remediation, London, Ontario. June 25-30, 1994). Undoubtedly, there are similarities in the reaction mechanisms of the different technologies as is evidenced by the similarities in PCE and TCE reaction intermediates and side products which include phosgene, dichloroacetyl chloride and trichloroacetyl chloride, and more highly chlorinated $\mathrm{C}_{1}$ and $\mathrm{C}_{2}$ organics. Nunez et al. (1993) [corona discharge], Evans et al (1993) [silent discharge plasma], and Nimlos et al (1993) [photocatalysis] all provide an excellent discussion of free-radical oxidation mechanisms from the viewpoint of a number of the most promising technologies.

\subsubsection{Electric Discharge Techniques}

These techniques employ high voltages (Ranging from 1 to 10 's of $\mathrm{kV}$ ) to generate electric discharges by stripping electrons from neutral gas molecules to partially ionize the gas. The electrodes are covered by a dielectric (typically glass) to separate them from the gas phase. The dielectric acts as a capacitor, eliminating arcing and promoting the formation of numerous micro 
discharges while serving to protect the electrode surfaces from the reactive gases. The discharges generate non-thermal, non-equilibrium plasmas in which the stripped electrons are not in thermodynamic equilibrium with the gas molecules (i.e. the electrons are "hot" while the other gas species are "cold"). The electrons discharged are highly reactive and catalyze the conversion of CVOC's. These types of discharges have been used successfully in electrostatic precipitators, ozone generators, and more recently in the abatement of $\mathrm{NO}_{\mathrm{X}}$ and $\mathrm{SO}_{\mathrm{x}}$ stack emissions. The advantages of these technologies are that reactions take place at ambient temperature and pressures and the energy consumption is relatively low. The disadvantage is that they are unproven for treatment of high-flow rate streams required for field operations.

\subsubsection{High Energy Corona}

The corona techniques are based on generating micro discharges with electrode geometry's that enhance electric fields and reduce the energy barrier necessary for electron discharge. The most preferred geometry involves the use of a concentric cylinder reactor with an axial wire electrode within a glass tube which acts as a dielectric barrier to a radial (e.g. wound coil or mesh screen) ground electrode. The discharges are generated with high voltage ac $(60 \mathrm{~Hz})$ or higher frequency power supplies. The reactant gases are passed through the annular space in the tube. (Nunez et al., 1993, Virden at al, 1992). The annular space is filled with a dielectric packing material that refracts the electric field, which establishes a uniform plasma distributed throughout the packing as opposed to the discrete microstreamers or discharges produced in a conventional silent discharge plasma. With the use of the packing material, the technique is actually a modified dielectric barrier discharge method. Because surface reactions appear to be important in electrical discharge plasmas, the packing can actually provide significant catalytic activity and the type of packing chosen can be optimized to maximize destruction. Furthermore, the packing material will also act as an adsorbent for the targeted organics, and the resulting chromatographic effect will increase the residence time of these vapors above that of air.

The EPA has been investigating corona destruction techniques since 1988 (Nunez et al., 1993). The first patent on a packed bed corona reactor was issued to the U.S. Army (Birmingham et al., 1990): Battelle Pacific Northwest Laboratory (PNL) has developed a high-energy corona system that was tested at the SRS. The system operates with a conventional $60 \mathrm{~Hz}$ frequency power supply and proper control of energy density eliminates problems with the formation of NOx.

\subsubsection{Cold Plasma}

The cold or "silent discharge" plasma process is very similar to the high-energy corona process except the discharge occurs across parallel rectangular plates separated by a dielectric. This geometry generates a high density of micro discharge events without the addition of a packed bed of dielectric beads as is required for the corona processing. The result is a significant reduction in the pressure drop across the reactor, which in turn, lowers energy requirements for processing. In addition, the reactor geometry results in an extremely low discharge inductance, allowing for the use of higher frequency pulse power supplies, which in turn, produce higher densities of electrons (current) and radicals. This same technique is used in commercial ozone generators. Los Alamos National Laboratory (LANL) developed a cold plasma treatment system that was tested at the SRS. 


\subsubsection{Photocatalytic Oxidation}

Photocatalytic oxidation refers to a process in which a contaminant is oxidized by free radicals formed from the interaction of light and oxidizing agents such as ozone and hydrogen peroxide, or a catalyst, such as titanium dioxide. The photocatalytic oxidation process typically uses an ultraviolet (UV) light source and one or a combination of the oxidizing agents or catalysts listed above. Use of auxiliary oxidants or catalysts facilitates the use of lower wavelength and lower intensity light sources relative to direct photolysis techniques. For organic compounds such as TCE or PCE, the oxidation process is actually multifaceted. The contaminant can be destroyed by direct photolysis through the molecular absorption of UV light (a small contribution at wavelengths of $>300 \mathrm{~nm}$ used in these processes), by interaction of the contaminant with the oxidant, by the oxidation of the contaminant by free radicals formed from photolysis of the oxidant, or free radical formation by interaction of the two oxidants such as ozone and hydrogen peroxide (Glaze et al., 1987; Ollis et al., 1991). The production of free radicals is the dominant mechanism in these systems (Glaze et al., 1987; Peyton and Glaze, 1988; Glaze and Kang, 1989a; Glaze and Kang, 1989b). Most work in this area has been done using an aqueous waste stream; however, for surface site interactions such as titanium-dioxide mediated processes, a vapor phase waste stream should be mitigated at similar if not increased rates due to a lower concentration or absence of radical scavengers. Some common scavengers in natural waters are inorganic carbon species and natural humic substances (Zafiriou, 1977; Fischer et al., 1987; Glaze and Kang, 1989b).

The technologies tested at the SRS used titania photocatalysis. The UV light at wavelengths < $390 \mathrm{~nm}$ excites valence electrons in the titania (anatase) semiconductor inducing an electron-hole pair. The electrons and holes that migrate to the surface serve as sites for the production of reactive ions and free radicals which react with the trichloroethylene (TCE) and perchloroethylene (PCE). Oxidation occurs at the "hole" sites to produce hydroxyl radicals and organic ions. Precious metals can be introduced as electron acceptors on the titania surface which reduce the probability of electron-hole recombination. These "bifunctional" catalysts have been investigated for several years as a means of splitting water to form oxygen and hydrogen. The advantages of this technology are the lower energy requirements and potential for lower capital costs.

Disadvantages include those inherent to heterogeneous catalysis in general, i.e. high pressure drops through the catalysts bed and catalyst deactivation. However, only those titania surfaces close enough to the light source are illuminated sufficiently to show activity (estimates show that nearly all of the incident radiation is absorbed in the first 10 microns of the catalyst pellets), therefore, an additional variable must be considered in reactor design beyond normal mass transfer limitation concerns. In addition, while the titania lowers the photon energy requirement for the incident light, the more refractive chlorinated organics (e.g. $\mathrm{CCl}_{4}$ and $\left.1,1,1-\mathrm{TCA}\right)$ are not as readily destroyed with this technique.

The University of Wisconsin, NuTech Environmental (formerly a Division of NuTech Energy Systems, Inc. of Canada and presently a separate corporation under the name Matrix Photocatalytic, Inc.), and International Technology (IT) Corporation (in a cooperative agreement with NREL) are all investigating photocatalytic oxidation of CVOCs using a titanium dioxide 
catalyst and ultraviolet light. All processes have differences in the way the catalysts or the light source is employed. The University of Wisconsin and NuTech processes were tested at the SRS.

\subsubsection{Vapor-Phase Photolytic Destruction}

CVOCs undergo photolysis when exposed to the proper electromagnetic frequency corresponding to the intramolecular bonding energy of the CVOC. The electromagnetic energy in this process can be supplied by any source that emits within the absorption band of the target contaminant. Most CVOC's have an absorption edge in the 200 to $250 \mathrm{~nm}$ range. Traditionally used sources have been low or moderate pressure continuous mercury vapor lamps (Wekhof, 1991) which have a strong but relatively narrow banded output at $254 \mathrm{~nm}$. These sources were used in water treatment processes with hydrogen peroxide or ozone, which have absorption bands in the vicinity of $254 \mathrm{~nm}$ leading to the formation of free radicals. The target contaminants are, therefore, oxidized predominantly by the free radicals formed rather than by direct photolysis since the 254 $\mathrm{nm}$ line is on the lower energy fringe of the TCE absorption band. The oxidation of the contaminant in this situation would depend on its refractivity and the refractivity of its intermediate breakdown byproducts to free radical attack. In contrast, a broad band UV source would have the advantage of supplying energy in the absorption bands of several contaminants as well as their intermediate photolytic byproducts (Wekhof, 1991). This would ensure a complete mineralization of the contaminant by successive photolytic reactions. Promising sources for broad band UV output are commercially available and custom built, pulsed xenon sources. Xenon flashlamps have a maximum near $230 \mathrm{~nm}$ with significantly higher output down to $200 \mathrm{~nm}$. This slight shift in wavelength results in an increase of one to two orders of magnitude in the molar extinction coefficient of most CVOC's.

Purus Inc. (San Jose, CA) has developed a vapor-phase pulsed UV photolytic process that utilized Xenon flashlamps for destruction of CVOCs. Their technology was tested at the SRS with support from Argonne National Laboratory. An initial pilot scale test of this technology was demonstrated at LLNL (Blystone, et al, 1991, 1992a)

\subsection{Separation Technologies}

With separation technologies, the gas-phase CVOCs are ultimately collected as a liquid phase that can either be destroyed in a concentrated form or recycled. A market currently still exists for TCE and PCE. Separation technologies can be direct condensation, or adsorption and desorption followed by condensation, or direct membrane separation.

\subsubsection{Regenerative Adsorption and Solvent Recycling}

The first step in the regenerative adsorption processes is essentially that described previously under carbon adsorption. While traditionally, granular activated carbon (GAC) is used, there are now commercially available units which use synthetic adsorbents (Blystone, et al., 1992b). These adsorbents are significantly more expensive, but offer improved capacity, are hydrophobic (adsorption isotherms are relatively independent of humidity levels) and can be regenerated, essentially, indefinitely. Once adsorbed, the CVOC is typically desorbed from the adsorbent with 
hot nitrogen gas. The hot concentrated gas stream is then processed through a refrigeration cycle (typically a simple Rankine cycle), where the solvent is condensed out and collected for recovery while the nitrogen is recycled back through the adsorbent bed. The NUCON BRAYSORB ${ }^{\circledR}$ process tested at the SRS, uses GAC with a Brayton refrigeration cycle in which some of the work required to compress (and reheat) the nitrogen is provided by a turbine driven from the gas expansion (cooling and condensation). During the cooling (or expansion part) of the cycle, the CVOC is condensed from the gas stream. This system has been successfully utilized to recycle solvents at manufacturing facilities (Jain, 1992).

\subsubsection{Gas-Phase Membrane Separation}

Gas-phase membrane separation is a mature technology where gas-phase components are selectively separated as they flow past a specially designed membrane with a structural and/or chemical make-up that makes them selectively permeable to certain gas molecules (Wijmans et al., 1990). Most of the work and applications to date are focused on separation of VOC's (as vapor) from aqueous streams (a process known as pervaporation). One disadvantage is that the current technology is more expensive than existing technologies, such as refrigeration cycles, mainly because the currently available membranes can only remove a fraction of the TCE or PCE from the waste stream per cycle thereby requiring multiple cycles. In addition, the gas must be compressed to high pressures to pass through the membrane and the membranes are not selective to organics, allowing appreciable water to pass through. Gas phase separation also places a premium on membrane quality and integrity, with small defects (e.g. pin-holes) capable of destroying selectivity. As with any separation technology, the efficiency of this technology is concentration dependent, with higher concentrations offering the needed driving force (i.e. gradient) for optimal efficiency. For these reasons, this technology is best suited for high concentration streams (> $5000 \mathrm{ppmv}$ ) and/or in combination with an off-gas destruction technology.

Membrane Technology Research Inc. teamed with the Westinghouse Hanford Company to develop a process for the removal of carbon tetrachloride. This membrane separation process was not tested at the SRS, but was going to be considered if it was successful at Hanford.

\subsection{Biodestruction Technology}

A gas-phase bioreactor can be used to aerobically break down TCE to carbon dioxide and chloride ions. The reactor uses a packed bed consisting of plastic beads on which a biofilm is maintained with a carbon/energy source and inorganic nutrients. Indigenous organisms capable of co-metabolizing TCE are stimulated to develop a biofilm. The advantage of this system is that the operating costs are minimal and no hazardous byproducts are produced. The disadvantages include maintaining a viable biofilm, the requirement of long residence times, and the temperature must be maintained around $20^{\circ} \mathrm{C}$ so that for environmental applications a controlled environment is necessary. These systems typically have little or no activity toward PCE destruction. "Work on similar technology has been done in the treatment of groundwater contaminated with TCE (e.g. Strandberg et al., 1989). 
The test of this technology at the SRS was a joint effort of the Savannah River Technology Center and Ecova Corp.

\subsection{Thermal Oxidation Technologies}

The direct oxidation of CVOC's typically occurs at temperatures above $700^{\circ} \mathrm{C}$, such as with incineration. By adding catalyst, the oxidation temperature can be reduced to as low as $350^{\circ} \mathrm{C}$, although TCE and PCE typically require temperatures in the 400 to $500{ }^{\circ} \mathrm{C}$ range for adequate destruction rates. These technologies are typically not considered incineration because the organics are not oxidized with an open flame (burning, such as with an incineration) and/or the process does not rely on radiative heat.

\subsubsection{Carbon Regeneration by Steam Reforming}

This process involves removal of TCE and PCE from a gas stream by adsorption onto granular activated carbon followed by steam desorption (at $260^{\circ} \mathrm{C}$ ) and subsequent high temperature oxidation (by water, not oxygen). The CVOC-laden steam is passed through a moving-bed reactor, that is packed with ceramic spheres coated with a slurry base. In the reactor, which operates at $700^{\circ} \mathrm{C}$, the CVOCs are dechlorinated. The reactor creates hydrochloric acid that is neutralized by the slurry base. The $\mathrm{HCl}$ depleted stream from the reactor is sent to a steam reforming reactor, which operates at $1500^{\circ} \mathrm{C}$, where all the undestroyed organic materials are completely mineralized to $\mathrm{CO}_{2}$ and $\mathrm{H}_{2}$. Synthetica Technologies (CA) has developed a portable unit capable of treating conventional 55 gallon drums of GAC. The operating costs are estimated to be about $\$ 1$ per $\mathrm{kg}$, although, there is limited data on treatment of chlorinated organics. The units are capable of 99.99 percent destruction efficiencies with all emissions from the system meeting air quality standards. With the use of a sodium bicarbonate slurry reactor, a significant fraction of the $\mathrm{HCl}$ is neutralized without having to use a post-treatment scrubbing process. A major advantage of the steam reforming process is a significant reduction in the formation of products of incomplete combustion found in more conventional incinerators (Nimlos et al., 1992). Sandia National Laboratories is investigating the use of rhodium supported catalysts in the reactor to reduce the required operating temperature. Disadvantages are that it requires high operating temperatures with streams that contain $\mathrm{HCl}$, so expensive materials of construction may be necessary and the fuel costs may be prohibitive. Also, a significant fraction of the carbon is consumed each time in the regeneration process.

Drums of activated carbon for this test were loaded at the SRS with TCE and PCE and shipped to the Synthetica Technologies Inc. in California for testing. At the present time, no information on the effectiveness of this technology has been provided to the authors.

\subsubsection{Pulsed Combustion}

This process involves a two stage thermal destruction method by combining incineration with thermal catalytic oxidation. The three primary variables which determine the efficiency of any gas or liquid phase incineration process are the time, temperature, and turbulence (known as the three $T$ 's) in the flame or combustion chamber. This technology optimizes these variables by using 
rapid fluid dynamic mixing in the combustion chamber and acoustic resonance to increase mass (and thermal) transport as the combustion gases exit through the chamber's tail pipe (Keller et al., 1990). The hot gas stream is then passed through a catalyst bed. Destruction efficiencies in excess of $99 \%$ have been achieved with methyl ethyl ketone. Work with this technology has concentrated on making thermal catalytic oxidation more energy efficient.

Sandia National Laboratory has cooperated with Engelhard on developing this technology. The system they are developing will treat flow rates up to $100 \mathrm{cfm}$. However, due to loss of funding, this technology was not tested in the field at the SRS.

\subsubsection{Thermal Catalytic Oxidation}

This technology was introduced in Chapter 2 as a "baseline" technique. However, its emergence as a reliable technology for CVOC's has occurred only within the last few years and there continues to be on-going improvements in the catalysts. For this reason, it is also included as a technology to be demonstrated.

Thermal catalytic oxidation utilizes a fixed or fluidized bed of supported noble metal catalyst at temperatures from 350 to $650^{\circ} \mathrm{C}$. The exact catalyst compositions are proprietary but are typically comprised of noble metal and metal oxides supported on alumina. Johnson Matthey, Engelhard, and Allied Signal are currently manufacturing catalyst for CVOCs. Flow rates are determined by the amount of catalyst and the required residence time for destruction of the CVOC. Typical gas hourly space velocities range from 5000 to $10000 \mathrm{hr}^{-1}$.

A test of a Johnson Matthey monolith catalyst was completed at the SRS. In addition, commercial off-gas treatment units employing the Allied Signal monolith catalyst have been used successfully at SRS to control emissions during tests of in-situ enhanced remediation technologies. 


\subsection{RESULTS AND DISCUSSION OF TECHNOLOGIES TESTED}

Below are brief summaries of the results of the technologies that were tested as part of the off-gas treatment program at the SRS. A more detailed description and analysis of the technologies can be obtained from the developers, researchers, etc., a list of which is given in the Appendix.

\subsection{Free Radical Oxidation Technologies}

\subsubsection{Vapor Phase Photolytic Destruction}

The test of the Purus Xenon flashlamp process was completed during March and April 1993. The test unit (FP-3) was equipped with four Xenon flashlamps each housed in a separate reactor chamber and capable of being independently controlled. The lamps operated at frequencies of 1 to $30 \mathrm{~Hz}$ with a maximum power input of $3.675 \mathrm{~kW}(0.48 \mathrm{~kW}$ to maintain a simmer arc plus 153 joules per pulse). Approximately $70 \%$ of the input power was transferred to the vapor stream. The unit is piped for split (parallel) flow between two sets of reactors (two reactor chambers per set). The unit was capable of flow rates from 5 to $100 \mathrm{scfm}$ (testing was done at rates from 25 to $100 \mathrm{scfm})$.

At the time of this writing, a final report is undergoing final editing by Argonne National Laboratory researchers (to be submitted as document no. ANL/ESD/TM/73). Therefore, only. limited data is available for publication in this report. The results show that TCE is effectively converted $(\geq 98 \%)$ at or beyond flashlamp frequencies of $3 \mathrm{~Hz}$ for TCE and at or beyond frequencies of $5 \mathrm{~Hz}$ for PCE. These conversions were noted for all flow rates and inlet concentrations (PCE concentrations ranged from 270 to $5500 \mathrm{ppm}$, TCE concentrations ranged from 10 to $900 \mathrm{ppm}$ ). The percent destruction has not been estimated and is complicated by an unpredictable trend in side product formation. Incomplete decomposition products such as chloroform (trichloromethane or CF), carbon tetrachloride (CT), phosgene, dichloroacetic acid (DCAA), trichloroacetic acid (TCAA), pentachloroethane (PCA) and hexachloroethane (HCA) were detected in the outlet. CT concentrations were generally less than 25 ppmv and showed a general increasing trend with increasing pulse frequency and concentration and decreasing residence time. Additionally, TCA that was in the inlet in lower concentrations (typically 10 to 20 $\%$ of the TCE concentration) usually went through unchanged. In general, $\mathrm{Cl}$ and $\mathrm{C} 2$ chloroalkanes are more difficult to oxidize with free radical techniques due in part to their higher ionization potential and lower extinction coefficient for light absorption in the applicable wavelength range of the lamps. In addition, there is evidence for a significant retarding effect from moisture on destruction efficiencies for $\mathrm{Cl}$ compounds which is likely due to either a competition effect and/or a radical scavenging effect (Evans, et al., 1993 and Bromberg, et al., 1993). 


\subsubsection{Photocatalytic Oxidation}

Two photocatalytic oxidation processes were tested at the SRS; the University of Wisconsin (UW) and the NuTech processes. There are several differences between the two processes. First, the UW process uses a mildly sintered sol-gel of titanium dioxide with a higher specific surface area $\left(150\right.$ to $\left.300 \mathrm{~m}^{2} / \mathrm{g}\right)$, while the NuTech process uses a fiberglass mesh support material for commercial grade titanium dioxide (approximately $50 \mathrm{~m}^{2} / \mathrm{g}$ ). Second, the UW reactor is thermally controlled with typical operation occurring at temperatures of 50 to $100^{\circ} \mathrm{C}$. Third, the NuTech process uses commercial tanning lamps which emit higher frequency radiation; the $U W$ system employs standard fluorescent black lights. In addition, the University of Wisconsin initially modified the water vapor content of the feed gas by passing the stream through a condenser at $0^{\circ}$ $\mathrm{C}$ (a second test with a larger scale unit did not incorporate water vapor control). While water is a necessary reactant in the oxidation mechanism, high humidity can result in excess adsorbed water blocking reactive sites on the catalyst surface. If control of water vapor is required, consideration must be given to the disposition of the secondary waste stream generated. Test with these technologies also brought to light a factor involving representative sampling procedures. Proper equilibration time prior to sampling is a critical parameter for photocatalytic technologies because the titania acts as an efficient absorbent for both water and the chlorinated organics. The absorption of organic species can lead to high observed conversions at the start of a run and low conversions when flow rates or concentrations are lowered or drop during a run. Such phenomena could also occur with any destruction technology that employs high surface areas (e.g. packed bed high-energy corona reactors, ozone enhanced [catalytic] oxidation)

\subsubsection{University of Wisconsin}

A portable laboratory-scale unit was tested in the field over a five day period in June of 1992 (Yamazaki-Nashida et al, 1994). The test reactor, an annular packed bed design with $4 \mathrm{~W}$ lamps, was operated at 55 to $60^{\circ} \mathrm{C}$ with data collected at three different flow rates $(40,100$, and 200 $\mathrm{cc} / \mathrm{min}$.) over a continuous operation time of roughly 72 hours. Laboratory studies had shown that at the slightly elevated temperatures, stoichiometric ratios of $\mathrm{CO}_{2}$ to CVOC (i.e. 2:1) could be achieved indicating complete destruction (Yamazaki-Nashida, et al 1993). The inlet gas-phase CVOC concentrations exhibited apparent diurnal fluctuations over the course of testing with levels ranging from $1900-7000$ ppmv of PCE, 222 - 1100 ppmv of TCE, 64 - 160 ppmv 1,1,1TCA, and $30-55$ ppmv 1,1-DCE. The conversion efficiency following an initial 24 hour equilibration period varied from 97 to 100 percent for TCE and from 88 to 99.9 percent for PCE. 1,1,1-TCA did not appear to be converted in the process. The only intermediate products detected were carbon tetrachloride (typically 40 to $100 \mathrm{ppmv}$ ) and chloroform (typically less than $10 \mathrm{ppmv}$ ). These concentrations represent molar conversions of approximately 2 percent to carbon tetrachloride and 0.2 percent to chloroform. Due to the unavailability of on-line or at-line analysis, there was no conclusive evidence to confirm the presence of other intermediates. The detection of carbon tetrachloride and chloroform suggest the likelihood of a chlorine radical addition mechanism which has been identified as a possible pathway for the formation of DCAC and phosgene by other research groups (Nimlos et al, 1993). 
A second field test of a larger scale system was conducted in November of 1993 . This second test included the use of at-line GC/ECD/FID analysis and on-line wet chemical methods for the derivatization and stabilization of reactive intermediates. The larger scale system consisted of two annular glass reactors operating with $40 \mathrm{~W}$ black lights (GE F40BLB) with maximum flow rates of approximately $5 \mathrm{lpm}$ per reactor. As with the first unit, the system was equipped with heaters and insulation to run at elevated temperatures; however, it was also possible to vary conditions of flow rate and temperature separately and run each reactor independently.

The reactors were operated continuously for 8 days (2000-4000 ppmv PCE for the first three days, 500-1000 ppmv PCE for the final 5 days). Phosgene was detected in the effluent only when inlet concentrations for PCE were above $3000 \mathrm{ppmv}$. Results for the latter five day run with one of the reactors are summarized in Table 6.1. Due to the small flow rates used in this system, the inlet concentrations from the extraction were again somewhat variable (since TCE concentrations are lower and TCE is more readily destroyed, only the results for PCE are presented here). Over the course of the five day run, operating temperatures and flow rates were varied. Conversion efficiencies for PCE fell below $99 \%$ only at temperatures above $100{ }^{\circ} \mathrm{C}$ (at these temperatures, water and organic adsorption onto the titania surface are significantly retarded). Complete conversion of 1,1,1-TCA appeared to be achieved, although the inlet levels were very low. The catalyst activity was not found to degrade over this time period. The major side product peak observed in the GC/ECD analysis was hexachloroethane. The maximum estimated concentration of hexachloroethane at the start of runs was less than $30 \mathrm{ppmv}$ (based on an assumed ECD response equal to that of PCE). This peak's area decreased steadily over the course of the run and given the high boiling point of hexachloroethane $\left(186^{\circ} \mathrm{C}\right)$, it is possible that some or all of the compound was formed in the initial phase of operation when inlet concentrations were much higher. The final adjustment included the addition of oxygen to the reactor feed which appeared to lower the hexachloroethane signal slightly and had little effect on the conversion. Additional energy is required to operate at these elevated temperatures, however, a considerable fraction of this energy is provided by the extraction pump and by the lamps (the actual energy requirement would amount to only a couple of kilowatts per $100 \mathrm{scfm}$ of flow).

\subsubsection{NuTech}

The NuTech system consists of 72 annular tube reactors. Each tube consists of a fiberglass-mesh coated titania catalyst wrapped around an ultra violet lamp (100W). The reactor was run in a dual pass mode ( 36 tubes per pass) at flow rates from 12 to $55 \mathrm{scfm}$. The test unit was based on a design for water remediation, and as such, had a significant pressure drop for vapor phase treatment (on the order of several psi). The unit was designed for flow rates up to $150 \mathrm{scfm}$ (at which the pressure drop requirements exceeded the capabilities of the SVE blower) and required $11 \mathrm{~kW}$ of power.

Four tests were run in succession at two different flow rates ( 25 and $50 \mathrm{scfm}$ ). The results are summarized in Table 6.2. The samples for these experiments were taken approximately one hour after the flow rate was established. Earlier experiments with shorter "equilibration" times gave inconsistent results. The fraction of TCE and PCE converted was inversely proportional to the flow rate, suggesting a residence time effect. Conversions ranged from 50 to 99 percent with the conversion of TCE higher than that for PCE at the lower flow rate tested ( $25 \mathrm{scfm})$ and slightly 
lower for the higher flow rate tested $(50 \mathrm{scfm})$. The soil contaminants also include small concentrations of 1,1-dichloroethylene (1,1-DCE) and trichloroethane. The 1,1-DCE was converted similar to TCE and PCE. However, the TCA was not affected by the system. This finding is consistent with results in the literature on the difficulty of destroying the saturated chloroethanes with photocatalytic methods. The results from these tests also revealed that as the conversions increased, the levels of detected side products also increased. Chloroform (CF) and carbon tetrachloride (CT) were detected in all of the first-pass and outlet samples (as these tests were run in succession, both CF and CT were eventually seen in inlet samples as a result of residual contamination in syringes and the $\mathrm{GC}$ ). The $\mathrm{GC}$ was not calibrated for $\mathrm{CF}$ and $\mathrm{CT}$ at the time of testing. Both CF and CT are not readily destroyed by photocatalysis.

Additional side products identified by NuTech in previous testing include pentachloroethane and hexachloroethane. These products were also identified in a previous test conducted at the SRS and were tentatively identified in select samples on the field GC during this test. In addition, two chromatographic peaks were observed between TCE and PCE for this test and tests of other free radical techniques. These two peaks are believed to be dichloroacetyl chloride and trichloroacetyl chloride and/or their derivatives or breakdown products (i.e. acetic acids, aldehydes, or acid anhydrides). It is suspected that the polychlorinated side products are indicative of the presence of molecular chlorine or chloride radicals. Small quantities of methylchloroformate, a derivative of phosgene obtained from bubbling trapped samples through methanol, were detected in two of the outlet samples with the GC/MS (low retention time peaks were also observed on the field GC chromatograms, but could not be clearly identified as phosgene or another potential chloride species). No calibration data for the derivatization of phosgene with the GC/MS are available.

\subsubsection{Electric Discharge Techniques}

For both electric discharge techniques (high-energy corona and cold plasma), the energy requirements were equivalent or higher than that used in thermal catalytic oxidation. However, conversion efficiencies were significantly higher than observed with full scale thermal catalytic units and it is typically more difficult to convert the last few percent of any vapor contaminant (although thermal catalytic systems do not produce the by-products observed with the free-radical techniques). Therefore, the actual power usage based on total mass converted may be lower for these discharge technologies or significantly less energy will be required to meet the $95 \%$ destruction criteria. In addition, these technologies are still in the developmental stage and no attempts to optimize the field units was made during the tests.

\subsubsection{High Energy Corona}

The High Energy Corona (HEC) process was tested during May 1993. The field test system was housed in a conventional mobile office trailer with separate control and process rooms (the egress point to the process room was equipped with interlocks to prevent entry during operation). The pilot scale system used $21 \mathrm{HEC}$ reactors configured in three independently operable banks connected in parallel. The reactors were packed with $6-\mathrm{mm}$ beads of common soda lime glass.

Each bank was run with a 7.5-kVA power supply capable of providing variable voltages up to 30 $\mathrm{kV}$. The test unit processed flow rates from 1 to $42 \mathrm{scfm}$ (residence times from 0.8 to 15.7 seconds) with pressure drops ranging from negligible to 4.5 inches of water. The CVOC 
concentrations ranged from 500 to $4000 \mathrm{ppmv}$ total with typical concentrations for the primary tests ranging from 600 to $800 \mathrm{ppm}$ of PCE and from 90 to $120 \mathrm{ppm}$ of TCE. A more detailed description of the equipment and results from this test can be found in Shah, et al, 1994.

The results of the field test are summarized in Table 6.3. Based on a fit of the test data, the residence times to achieve $99 \%$ conversion efficiency were $1.2 \mathrm{~s}(31.5 \mathrm{cfm})$ for TCE and $5.1 \mathrm{~s}$ $(6.4 \mathrm{cfm})$ for PCE. Due to the sole use of the FID detector on all inlet samples, there was insufficient data on the inlet concentration of TCA to determine how effective the technique is on saturated chlorocarbons. (outlet concentrations were in the $10 \mathrm{ppm}$ range, suggesting that conversion of TCA was significantly lower than that seen for TCE and PCE). Detected side products included trichloronitromethane, phosgene, chloroform, carbon tetrachloride, di- and trichloroacetyl chlorides (typically as acetates), and penta- and hexa-chloroethanes. The formation of reactive intermediates was inversely proportional to reactor residence time. While the trend was not monotonic, with the reactive species such as $\mathrm{COCl}_{2}$ and DCAC and TCAC combined with their low concentrations, the results are probably affected by the limits of the bag sampling procedure. There was, in addition, an apparent effect on the formation of these species with changes in relative humidity. The relative change in detector response for these species increase nearly three fold (from $<1.5 \%$ of the total inlet carbon, to $<4.2 \%$ ) as the inlet relative humidity was increased from 45 to 90 percent. No change in the conversion efficiency for TCE and PCE was observed over this range, but an approximate $10 \%$ increase in power was necessary to process the off-gas stream at higher humidity. The pilot plant had a humidity control capability (to add to, not decrease the moisture levels) as the corona technique operates with greater discharge stability (and consequently, better destruction efficiency) at a relative humidity approaching 50 percent. An approximate power level of $15 \mathrm{~kW}$ was required for processing over the range of operating parameters tested.

\subsubsection{Cold Plasma}

A test of the Cold Plasma technology was completed during September and October 1993. The field unit consisted of two cell banks ( 20 cells per bank) and was capable of handling flow rates up to approximately $3.3 \mathrm{scfm}$ (95 liters/min.) with a power consumption of 15 to $17 \mathrm{~kW}$. A high frequency amplifier was used and operated at $1500 \mathrm{~Hz}$ delivering from 4 to $5 \mathrm{~J}$ per pulse (cycle). The unit was equipped with a caustic scrubber to neutralize acidic products.

The results from the field tests are summarized in Table 6.4. Conversions of greater than $99 \%$ were obtained for TCE over a broad range of energy densities ( 3.71 to $16.14 \mathrm{~J} / \mathrm{cm}^{3}$ ), concentrations, and flow rates. PCE conversions were also equal to or greater than $99 \%$ over the whole range of test parameters. The best conversion achieved for TCA was about $99 \%$ at 13.98 $\mathrm{J} / \mathrm{cm}^{3}$. The mineralization of the VOC's was incomplete as about 20 small incomplete decomposition products were observed for most of the runs. Representative chlorocarbon byproducts identified were the input CVOCs (PCE, TCA, TCE), as well as carbon tetrachloride, chloroform, dichloroacetic acid (DCAC), trichloroacetic acid (TCAA), hexachloroethane, and phosgene (which is easily destroyed by the water scrubber). The partitioning of these byproducts and the absolute concentrations have not yet been determined and are the subject of further testing by LANL. 
The power delivered into the gas was generally around 6 to $7 \mathrm{~kW}$. Previous laboratory studies showed that a power output of $9.4 \mathrm{~kW}$ would be required for $95 \%$ conversion. Therefore, the unit performed more efficiently than anticipated. This result may be due in part to additional energy imparted to the gas through corona discharges at the ends of the cell plates. The power supply is about 75 to $80 \%$ efficient and slightly more than one-half of the power supply output was delivered into the gas; most of the remainder went to dielectric losses in the Pyrex (the dielectric used to line the plates). The driver circuit was also not optimum for the load. Many factors affect circuit performance; some of which were unknown until actual operation.

The partial pressure of water vapor from the well remained fairly constant around 12 Torr until the final run day where it dropped to 8 Torr (It was a cold day and some water may have condensed out in the well piping.). This occurred during the low flow rate runs where the well gas was diluted with cold atmospheric air. There appears to be a good correlation between water vapor concentration and ease of destruction. For four runs with only 8 Torr of water vapor present and at the higher cell energy densities $(269,110,226$, and $233 \mathrm{~W} / \mathrm{liter} / \mathrm{min}$., respectively), the conversion is less, which may indicate less water vapor is yielding lower hydroxyl radical concentrations. However, laboratory studies have shown that conversions are lower in moist streams (Evans, et al., 1993). This effect is likely a consequence of the interaction of molecular water and/or hydroxyl radicals with chloride and oxychloride radicals which are suspected chain propagators.

\subsubsection{Ozone Enhanced Oxidation}

Testing of the Ultrox D-TOX ${ }^{\mathrm{TM}}$ Pilot Plant took place during February and March of 1993 . The test unit was capable of handling flow rates up to $100 \mathrm{scfm}$, although, at the vacuum levels required at the well, the actual flow rate was $45 \mathrm{scfm}$. This technology uses a proprietary catalyst for ozone activation and free-radical formation and, as such, differs from the more conventional use of UV radiation with ozone that produces oxygen and hydroxyl free radicals. The unit consisted of five major components: 1) Electric preheater; 2) An air compressor / ozone generator (28 lb, PCI Model G-28); 3) Two parallel D-TOX ${ }^{\mathrm{TM}}$ catalyst beds; 4) A solid granular-type sorber (calcium and sodium hydroxide); and 5) An ozone decomposition catalyst chamber (Decompozon $^{\mathrm{TM}}$, which removes residual ozone to below the OSHA regulation limit of $0.1 \mathrm{ppm}$ ). The power requirement for the complete system was approximately $50 \mathrm{~kW}$ ( $40 \mathrm{~kW}$ for the air compressor / ozone generator and $5 \mathrm{~kW}$ each for the pre heater and blower). The influent vapors were diluted with outside air by a control valve which was installed at the vapor inlet. The vapor concentration was controlled by air dilution in a range of 100 up to 2,000 ppmv. PCE was the major contaminant consisting of over $90 \%$ of the total vapor influent (mass basis). The remainder of the chlorinated solvents were TCE and TCA. The ozone to CVOC ratio could be varied from $<1$ to $10(\mathrm{w} / \mathrm{w})$.

Table 6.5 summarizes results for tests conducted over two days of operation. The samples that were taken and analyzed showed that the main by-product other than hydrogen chloride was carbon tetrachloride. When the ozone to VOC ratio was below $1: 1$ weight to weight $(w / w)$, additional by-products were formed such as chloroform, pentachloroethane, and hexachloroethane. Therefore, by controlling the ozone ratio in the Ultrox system, the by-product 
formation can be minimized. Whenever the ozone is in excess, there is an increase in the system performance.

In addition to the ozone to VOC ratio, humidity played a minor role in the formation of the byproducts. The overall destruction efficiency did not change over a wide range of humidity content in the influent vapor. However, when the influent vapor was over saturated with water, there was an increase in the by-products formation (The site was located outside and due to the drastic weather changes, mist was mixed in with influent stream). During the pilot study, the analytical data showed a tentatively identified compound trichloronitromethane (TNM) at an approximate concentration of 0.7 to $7 \mathrm{ppmv}$. Possibly, TNM was formed when the ozone generator cooling water was running 20 to 30 oF higher due to a chiller failure. In addition, fugitive emissions of CVOC's could at times be picked-up by the air compressor, and this might have formed the TNM in the dialectics within the ozone generator. (A pilot demonstration conducted in Michigan following the test at SRS detected no TNM as a by-product)

When CVOCs react with ozone in the catalyst bed, it is possible to form phosgene as a byproduct. The phosgene was detectable with the GC/MS technique as methylchloroformate (formed when the sample is bubbled through a methanol solution). Phosgene was detected below the standard reporting limit of $0.5 \mu \mathrm{g} / \mathrm{l}$ when the Ultrox process was treating over $6,000 \mu \mathrm{g} / \mathrm{lof}$ TCE and PCE. A more sensitive and accurate method (EPA Method T06) for analyzing phosgene was used at a Michigan site demonstration. With a method detection limit of $0.1 \mathrm{ng} /$, the phosgene concentration was $9 \mathrm{ng} / \mathrm{l}$ at the Michigan test site.

\subsection{Separation Technologies}

\subsubsection{Regenerative Adsorption and Solvent Recycling}

The NUCON BRAYSORB ${ }^{\circledR}$ pilot plant was operated in the field over a two week period in April 1993. The typical gas-phase concentrations for PCE and TCE during operation were $6000-7000$ ppmv and 500 to $1000 \mathrm{ppmv}$, respectively. To extend the breakthrough time for the carbon beds at these high concentrations, a $75 \mathrm{scfm}$ stream was used (the pilot unit is capable of handling flows up to $250 \mathrm{scfm}$ ). The beds were run in series to load the first bed to its capacity. This reduces the equipment size requirements and extends the cycle time. In addition, by saturating the carbon in the first bed, most of the adsorbed water is driven off before regeneration. This reduces the amount of secondary waste and reduces the likelihood of "freeze-up" problems in the refrigeration cycle. The unit required approximately $45 \mathrm{~kW}$ of power and a source of liquid nitrogen which is used to purge the system of oxygen (to both reduce flammability and explosive limits, and extend the regeneration life cycle of the carbon) and as the working fluid during regeneration.

The test involved six adsorption-regeneration cycles with breakthrough times varying from 10 to 13 hours and regeneration times requiring approximately 4 hours. A total of approximately 500 pounds of solvent were recovered. In addition, nearly 50 pounds of water was also collected, although the bulk of this secondary waste was recovered in the pre-chiller for the carbon beds. The pre-chiller is normally used to lower the inlet temperature of the solvent laden gas stream fed 
to the carbon beds to enhance adsorption capacity. However, at the high inlet solvent concentrations particular to the test well and at the high relative humidity generally encountered with soil vacuum extraction feed streams, use of the pre-chiller led to the direct condensation of solvent and water vapors and, therefore, was not used after this discovery was made during the first cycle. The working capacity of the carbon beds ( 200 pounds each) was 46.5 percent with a recovery efficiency greater than 97 percent (at lower feed concentrations, the beds are capable of greater than $98 \%$ removal efficiency). The beds were desorbed with nitrogen at 325 oF. Due to the relatively low vapor pressures of PCE and TCE at the typical operating temperatures of the Brayton cycle $\left(-20\right.$ to $\left.-100^{\circ} \mathrm{C}\right)$, the majority of solvent ( $>99$ percent) was recovered in the first separator following initial cooling and prior to the expansion of the recycled gas stream.

An additional discovery made during the test involved the potential for cross-contamination of waste streams processed by a de-coupled recovery unit (e.g. dedicated carbon beds regenerated with a leased or purchased mobile recovery unit). This potential was apparent by the detection of toluene (and trace quantities of xylenes) in the recovered solvent and in gas analyses made at the process lines feeding and exiting the carbon beds. These residual solvents were retained in the system from a test of the unit prior to its arrival at the SRS.

The composition of the material collected (as determined by GC/MS) was 458 pounds PCE, 48 pounds water, 36.4 pounds TCE, 3 pounds toluene, and 1.6 pounds 1,1,1-trichloroethane. The toluene and water were undesirable components of the collection, because the water would need to be separated from the mixture and toluene is combustible and explosive.

\subsection{Biodestruction Technology}

A bioreactor system utilizing Pseudomonas cepacia G4 bacteria, along with nutrients and phenol for growth, to biologically degrade TCE was operated in a seven week test during March and April of 1994. ECOVA Corporation constructed and provided an inoculum for an off-gas bioreactor system to treat trichloroethylene (TCE) in the water phase. The system design is to biologically mineralize TCE and pass other CVOC's, if present in influent off-gas, along to a secondary treatment system. Gases containing CVOC's were delivered by a vacuum pump operating at approximately 2-5 scfm. The two main components of the gas phase bioreactor system are a scrubber for transferring CVOCs from the gas phase to the liquid phase, and a fermenter for maintaining the microbial population. The system also includes a skid that supports a water heater and water filter, centrifugal and metering pumps, a blower, a 200-gallon nutrient tank, the system control panel, and safety equipment (fire extinguisher, eye wash, and first aid kit). Additional off-skid items included influent and effluent storage tanks, and a phenol drum. The system drew 10 and 40 full load amps at 480 volts depending on the load required from the heater used to maintain the fermenter and reactor at $20^{\circ} \mathrm{C}$.

The influent gas delivered from the extraction well averaged $12 \%$ TCE of the total CVOC's detected. At progressively higher sampling ports in the scrubber tower (upgradient in recycle flow) TCE composition percentages dropped due to a higher scrubbing efficiency for TCE relative to PCE. The scrubber effluent averaged about $9 \%$ TCE. Since $P$. cepacia $\mathrm{G} 4$ does not cometabolize PCE, PCE masses in the influent and effluent gases should closely correspond 
assuming no other physical gains or losses (e.g., photolysis, stripping, adhesion, adsorption, chemical reaction). These values varied greatly between sampling points and effluent masses for both compounds were often higher than influent masses. The first week following the second inoculation, a weekly average difference of $29 \%$ in exiting percentages was detected. The exiting difference in CVOC ratio's decreased the longer the system operated. This was due to the decrease in the population of $P$. cepacia $\mathrm{G} 4$. Phenol removal remained high but TCE degradation decreased the longer the system operated. The test length was insufficient to reach homeostasis, given the operation variables encountered during startup. Tests of this type must in the future operate for longer periods of time, under less variable operating conditions.

\subsection{Thermal Oxidation Technologies}

\subsubsection{Carbon Regeneration by Steam Reforming}

Drums of activated carbon were loaded with an off-gas stream at the In-Situ Bioremediation Demonstration Site and shipped to Synthetica Technologies, Inc. in April 1992. The drums were loaded by operating with two drums in series at flow rates from 50 to $60 \mathrm{scfm}$ and inlet concentrations of 140 to 170 ppmv PCE and 90 to 100 ppmv TCE. The drums were not analyzed until the following fall. Analysis with methanol extraction revealed that the first drums in each series contained all of the PCE. Additional trace contaminants (including TCA, 1,1-DCE, and Freon-11 or trichloro-fluoromethane) were only detected on the second drum from each series. Calculated loadings from the analyses were significantly lower than anticipated. However, CVOC loses could have resulted from the drums being vented during shipment and storage. In addition, no calculated recovery efficiency was given for the methanol extraction method used. Synthetica did not complete tests on the drums of activated carbon because of operating problems with the process which were mainly associated with materials of constructions. At high temperatures, the $\mathrm{HCl}$ is extremely corrosive.

\subsubsection{Thermal Catalytic Oxidation}

The test of a Johnson-Matthey halocarbon destruction catalyst was conducted during December, 1992. The test unit was a small-scale reactor capable of handling flows from $<1 \mathrm{scfm}$ to approximately $10 \mathrm{scfm}$. The unit was equipped with a flow sensor and temperature controller.

Results from the tests are summarized in Table 6.6. The catalyst effectively destroyed both TCE and PCE at temperatures above $500^{\circ} \mathrm{C}$ and gas hourly space velocities ranging from 10,000 to $30,000 \mathrm{hr}^{-1}$. A dramatic drop in the PCE destruction efficiency was observed at temperatures below $500^{\circ} \mathrm{C}$. The primary side products observed were 1,1-DCE, which is in the feed at low concentrations but is also an identified by-product of TCA oxidation. In addition, trace quantities of chloroform (less than 2 ppmv) were found in certain samples. 
Table 6.1 Summary of Results from University of Wisconsin Photocatalytic Oxidation Test

\begin{tabular}{|c|c|c|c|c|c|}
\hline $\begin{array}{c}\text { Cumulative } \\
\text { Time } \\
\text { On Stream } \\
\text { (hrs) }\end{array}$ & $\begin{array}{c}\text { Flow Rate } \\
\text { (lpm) }\end{array}$ & $\begin{array}{c}\text { Temp. } \\
\text { (oC) }\end{array}$ & $\begin{array}{c}\text { Average Inlet } \\
\text { PCE Conc'n } \\
\text { (ppmv) }\end{array}$ & $\begin{array}{c}\text { Average } \\
\text { Conversion } \\
(\%)\end{array}$ & $\begin{array}{c}\text { C2C16 } \\
\text { GC Response } \\
\text { (Relative to t=0) }\end{array}$ \\
\hline 24 & 2 & 80 & 674 & 99.67 & 1 \\
\hline 50 & 2 & 110 & 734 & 96.63 & 0.14 \\
\hline 84 & 1 & 100 & 412 & 99.78 & 0.05 \\
\hline 110 & 0.5 & 100 & 574 & 99.85 & 0.06 \\
\hline 116 & $1 *$ & 100 & 447 & 99.94 & 0.02 \\
\hline
\end{tabular}

* includes $0.5 \mathrm{lpm}$ of oxygen added to feed

Table 6.2 Summary of Results from NuTech Photocatalytic Oxidation Test

\begin{tabular}{|c|c|c|c|c|c|c|c|}
\hline $\begin{array}{c}\text { RUN } \\
\text { Flow Rate }\end{array}$ & $\begin{array}{l}\text { Reactor } \\
\text { Location }\end{array}$ & $\begin{array}{c}\mathrm{TCE} \\
\text { (ppmv) }\end{array}$ & $\begin{array}{l}\text { Fraction } \\
\text { Converted }\end{array}$ & $\begin{array}{c}\text { PCE } \\
\text { (ppmv) }\end{array}$ & $\begin{array}{l}\text { Fraction } \\
\text { Converted }\end{array}$ & $\underset{\text { (Area/1000) }}{\mathrm{CHCl}_{3}}$ & $\underset{\text { (Area/1000) }}{\mathrm{CCl}_{4}}$ \\
\hline \multirow[t]{3}{*}{$50 \mathrm{scfm}$} & inlet & 138 & & 1025 & & 4.3 & 0 \\
\hline & half-pass & 100 & 0.275 & 538 & 0.475 & 42.8 & 32.7 \\
\hline & full-pass & 57 & 0.587 & 370 & 0.639 & 96.1 & 75.9 \\
\hline \multirow[t]{3}{*}{$25 \mathrm{scfm}$} & inlet & 152 & & 909 & & 2.4 & 0 \\
\hline & half-pass & 107 & 0.296 & 888 & 0.023 & 56.6 & 107.0 \\
\hline & full-pass & 20 & 0.868 & 211 & 0.768 & 83.6 & 212.7 \\
\hline \multirow[t]{3}{*}{$25 \mathrm{sefm}$} & inlet & 112 & & 702 & & $13.1^{*}$ & 0 \\
\hline & half-pass & 52 & 0.536 & 381 & 0.457 & 75.8 & 71.6 \\
\hline & full-pass & 6 & 0.946 & 84 & 0.88 & 72.6 & 133.5 \\
\hline \multirow[t]{3}{*}{$50 \mathrm{scfm}$} & inlet & 109 & & 881 & & $73.4^{*}$ & $5.8^{*}$ \\
\hline & half-pass & 78 & 0.284 & 591 & 0.329 & 81.7 & 32.4 \\
\hline & full-pass & 55 & 0.495 & 417 & 0.527 & 165.4 & 81.3 \\
\hline
\end{tabular}

* Suspected residual contamination from previous samples 
Table 6.3 Summary of Results from High-Energy Corona Destruction Test

\begin{tabular}{|c|c|c|c|}
\hline $\begin{array}{c}\text { Flow Rate } \\
(\mathrm{cfm})\end{array}$ & $\begin{array}{c}\text { Residence Time } \\
(\mathrm{sec})\end{array}$ & $\begin{array}{c}\text { TCE Conversion } \\
(\%)\end{array}$ & $\begin{array}{c}\text { PCE Conversion } \\
(\%)\end{array}$ \\
\hline 1.4 & 15.7 & $>99$ & $>99^{*}$ \\
\hline 10.5 & 3.1 & $>99$ & 93.9 \\
\hline 21.0 & 1.6 & $>99$ & $74.6^{* *}$ \\
\hline 42.0 & 0.8 & 97.1 & 72.9 \\
\hline
\end{tabular}

* Analyzed with an on-line GC/FID; ** Average of four runs

Table 6.4 Summary of Results from Cold Plasma Destruction Test

\begin{tabular}{|c|c|c|c|c|c|c|c|c|}
\hline $\begin{array}{c}\text { Flow Rate } \\
(\mathbf{p m})\end{array}$ & $\begin{array}{c}\text { Energy } \\
\text { Density } \\
\text { (W/1pm) }\end{array}$ & $\begin{array}{c}\text { Water } \\
\text { Vapor } \\
\text { (torr) }\end{array}$ & $\begin{array}{c}\text { PCE Inlet } \\
(\mathbf{p p m v})\end{array}$ & $\begin{array}{c}\text { Conversion } \\
(\%)\end{array}$ & $\begin{array}{c}\text { TCE Inlet } \\
(\mathbf{p p m v})\end{array}$ & $\begin{array}{c}\text { Conversion } \\
(\%)^{* * *}\end{array}$ & $\begin{array}{c}\text { TCA Inlet } \\
(\text { ppmv) }\end{array}$ & $\begin{array}{c}\text { Conversion } \\
(\%)\end{array}$ \\
\hline 95.5 & 61.8 & 11.4 & 4770 & 99.93 & 648 & 99.99 & 92.9 & 94.29 \\
\hline 95.5 & $-*$ & 11.7 & 744 & $99.93^{* *}$ & 88.0 & 99.94 & 10.6 & 90.66 \\
\hline 95.5 & 74.5 & 12.2 & 776 & $99.94^{* *}$ & 83.7 & 99.94 & 10.5 & $95.24^{* *}$ \\
\hline 95.5 & 74.2 & 11.8 & 632 & 99.63 & 77.9 & 99.94 & 10.4 & $99.52^{* * *}$ \\
\hline 60 & 110 & 11.8 & 775 & $99.94^{* *}$ & 106 & 99.95 & 11.8 & 94.85 \\
\hline 30 & 269 & 5.8 & 172. & 98.76 & 31.0 & $99.36^{* *}$ & 5.28 & $99.05^{* * *}$ \\
\hline 60 & 110 & 8.1 & 4360 & 99.97 & 578 & 99.99 & 84.6 & 94.94 \\
\hline 30 & 226 & 8.6 & 5900 & 99.88 & 782 & 99.99 & 110 & 97.21 \\
\hline 30 & 233 & 8.1 & 5750 & 99.91 & 766 & 99.99 & 107 & 98.22 \\
\hline
\end{tabular}

* Not measured

** Chromatographic peak identified and integrated in outlet sample, but area < lowest calibrated standard of 1 ppmv. Concentrations estimated as 0.5 ppmv PCE, 0.2 ppmv TCE, and 0.5 ppmv TCA

*** Chromatographic peak not detected and/or integrated in outlet sample. Concentration estimated at 0.05 ppmv 
Table 6.5 Summary of Results from Enhanced Ozone Oxidation Test

\begin{tabular}{|c|c|c|c|c|c|c|}
\hline $\begin{array}{c}\text { Catalyst Temp., } \\
\text { ('F) }\end{array}$ & $\begin{array}{c}\text { Ozone:CVOC } \\
\text { Ratio } \\
(\mathbf{w} / \mathbf{w})\end{array}$ & $\begin{array}{c}\text { Total CVOC } \\
\text { Conversion } 1 \\
(\%) \\
\end{array}$ & $\begin{array}{l}\text { TCE Inlet } \\
\text { (ppmv) }\end{array}$ & $\begin{array}{c}\text { Conversion } \\
(\%)^{2}\end{array}$ & $\begin{array}{l}\text { PCE Inlet } \\
\text { (ppmv) }\end{array}$ & $\begin{array}{c}\text { Conversion } \\
(\%)^{2}\end{array}$ \\
\hline 190 & $1.5: 1$ & 92.9 & 82 & 100 & 560 & 99.23 \\
\hline $200^{3}$ & $1.1: 1$ & 96.8 & 102 & 100 & 736 & 99.53 \\
\hline 210 & $1: 1.25$ & 97 & 152 & 100 & 1153 & 99.96 \\
\hline 220 & $1: 1.3$ & 97.8 & 142 & 100 & 1105 & 99.89 \\
\hline 240 & $1: 2.5$ & 96.3 & 214 & 100 & 1714 & 99.97 \\
\hline 240 & $1: 1.75$ & 93.6 & 207 & 99.36 & 1572 & 97.45 \\
\hline 250 & $1: 1.5$ & 94.5 & 184 & 100 & 1383 & 99.85 \\
\hline 250 & $1: 1.35$ & 92.3 & 168 & 100 & 1193 & 100 \\
\hline $250^{3}$ & $1: 1.5$ & 94.5 & 173 & 100 & 1299 & 98.76 \\
\hline 210 & $1.5: 1$ & 95.3 & 70 & 97.20 & 452 & 98.50 \\
\hline 200 & 1.3:1 & 96.2 & 85 & 98.47 & 573 & 99.31 \\
\hline
\end{tabular}

1) Total CVOC Conversion includes TCA conversion and the formation of organic intermediates: chloroform (estimated based on TCE response curve), carbon tetrachloride, and hexachloroethane (both estimated based on PCE response curve)

2) $100 \%$ conversion listed for outlet samples with analysis below detection limit.

3) Single catalyst bed. (Normal parallel beds space velocity $=225 \mathrm{hr}^{-1}$ )

Table 6.6 Summary of Results from Thermal Catalytic Oxidation Test Johnson-Matthey Catalyst

\begin{tabular}{|c|c|c|c|c|c|}
\hline $\begin{array}{c}\text { Temp. } \\
\text { (C) }\end{array}$ & $\begin{array}{c}\text { GHSV } \\
\left(\mathbf{x 1 0} \mathbf{-}^{-3}\right)\end{array}$ & $\begin{array}{c}\text { PCE Inlet } \\
(\mathbf{p p m v})\end{array}$ & $\begin{array}{c}\text { Conversion } \\
(\%)\end{array}$ & $\begin{array}{c}\text { TCE Inlet } \\
(\mathbf{p p m v})\end{array}$ & $\begin{array}{c}\text { Conversion } \\
(\%)\end{array}$ \\
\hline 600 & 30 & 1066 & 99.9906 & 81 & 99.9753 \\
600 & 20 & 953 & 99.9895 & 63 & 99.8413 \\
550 & 30 & 1316 & 99.9924 & 94 & 99.9787 \\
550 & 20 & 658 & 99.6960 & 77 & 99.9740 \\
550 & 20 & 1390 & 99.9928 & 109 & 99.9083 \\
500 & 20 & 755 & 99.6026 & 76 & 98.6842 \\
500 & 20 & 698 & 96.8481 & 49 & 99.7959 \\
450 & 20 & 1727 & 50.2606 & 179 & 88.8268 \\
450 & 20 & 805 & 32.9193 & 61 & 99.8361 \\
\hline
\end{tabular}




\subsection{ECONOMIC ANALYSIS}

\subsection{Introduction}

This chapter discusses some of the economic aspects of full-scale use of the technologies tested. However, due to the broad range of technology development encountered, it is difficult and highly speculative to present a complete "even-playing-field" comparison. For that reason, this chapter will focus on the cost analysis for baseline technologies, in particular, thermal catalytic oxidation which has been used at full scale ( $>100 \mathrm{scfm}$ ) for extended periods (from a few months to greater than one year of continuous operation) in demonstrations at the SRS. Since the baseline technologies are "proven", some estimates of full costs (including maintenance, labor, replacement parts, etc.) are presented.

The most speculative issues with regard to technology commercial application involve capital costs and operating reliability. The former issue assumes that any technical aspects related to continued performance with scale-up are resolved adequately. The latter issue can not be estimated without further demonstrations involving extended time-on-stream tests. For these reasons, unresolved technical issues related to full scale commercial operation of the technologies tested will be discussed in this chapter. For the technologies involving commercial units, current information on costs provided by the vendors will be presented. However, the authors encourage readers to contact the vendors to obtain costs for their particular application (see Appendix).

Since adequate energy use information was obtained from the demonstrations, a comparison of the different energy requirements will be made. However, as mentioned previously, many of the technologies have not been optimized with respect to energy use. Therefore, the numbers generated in this study should be viewed as upper limit "current status" energy requirements. Where appropriate and available, potential avenues for improving energy requirements will be presented.

As a final note to this introduction, a discussion of cost basis is appropriate. Technology costs for off-gas treatment are typically presented on a per kilogram of CVOC destroyed or removed basis. For the most part, all of the technologies tested were able to meet the performance goal of $95 \%$ destruction or removal (although more extensive sampling techniques for side products and/or reactive intermediates are required to determine the true destruction efficiency). In addition, similar feed concentrations were used for each test, with concentrations ranging from a few hundred to a few thousand parts per million by volume (ppmv). Flow rates, however, varied widely. Typical SVE applications involve flow rates from ten's to a few thousand scfm. Since the concentration ranges for each of the technologies are comparable, we will focus our baseline cost - analysis on a cost per scfm basis. 


\subsection{Baseline Technology: Thermal Catalytic Oxidation}

In support of three in-situ remediation technologies, SRTC has operated two off-gas treatment units employing thermal catalytic oxidation systems. One system was designed for dedicated service to the In-Situ Bioremediation (ISBR) Demonstration. The second was a smaller portable skid mounted unit used in support of the In-Situ Heating (ISH) Demonstrations. Both systems used electrical heating and Allied Signal Halocarbon Destruction monolith catalysts (HDC-t). Table 7.1 lists the operating ranges and capital cost information for each of these units (additional information on these units can be found in Saaty, et al., 1994; Lombard et al., 1993; and Jarosch, et al., 1993). The major replacement part costs for these units is the catalyst (costs are listed within the table), which has a typical lifetime of three to five years. Replacement frequency, however, is very dependent on environmental conditions (e.g. CVOC concentrations, presence of catalyst poisons in the off-gas, etc.). In addition, the heating elements (silicon carbide rods) may need periodic replacement but appear to last approximately as long as the catalyst (units require about 6 rods per $100 \mathrm{scfm}$ and rod costs are approximately $\$ 100 \mathrm{each}$ ). Maintenance on the units is limited to replacement of the catalyst and rods.

The observed energy requirements result in a cost of $\$ 5.18 / \mathrm{kg}$ for the ISBR unit and $\$ 3.63 / \mathrm{kg}$ for the ISH unit (assuming $\$ .07 / \mathrm{kW}-\mathrm{hr}$ ). These costs do not include the energy required to initially bring the units up to temperature (typically a period of 24 hours). This additional energy is fairly insignificant unless the units have considerable down time. Both of the units operated well below maximum CVOC concentrations (approximately 2500 ppmv total assuming a 1:1 PCE:TCE stream). This illustrates a point presented earlier, that the energy use of thermal catalytic systems are essentially independent of concentration (this is especially true for CVOC's which have approximately $10 \%$ of the heating value of typical fuel gases). In addition, the units are electrically heated, and, therefore, require approximately fifty percent more in energy costs than a natural or propane gas heated unit (capital costs for electrical units are also higher). An estimate of the total yearly cost for the ISH unit is given in Table 7.2. This table is provided to illustrate a point regarding the relative cost of energy. The estimate shows that energy costs amount to less than 30 percent of the total operating costs. The largest fraction for this estimate is capital and replacement parts (note that this analysis assumes a greater catalyst replacement frequency than estimated by the vendor). Labor, the bulk of which involves only one hour per operating day of monitoring, is the largest single item cost (Note that these costs are for the oxidation unit only, additional labor is associated with the SVE unit and costs incurred for sampling and analysis). Nearly any cost estimate for remediation technologies will show that labor costs can far exceed other operating expenses. This is the major reason that a more in depth economic analysis for most of the emerging technologies is speculative at best until a more reasonable estimate of the true reliability (including "ease" of operation) of the equipment can be made. Such an estimate can only be made with extended tests with near full scale units.

\subsection{Comparison of Energy Requirements}

A listing of the energy requirements per $100 \mathrm{scfm}$ of off-gas flow for most of the technologies tested are presented in Table 7.3. These numbers are based on observed field performance and/or from vendor quoted performance (discrepancies are generally noted in the comments). It should 
be emphasized that field numbers have not been adjusted to account for observed conversion efficiencies greater than $95 \%$ (i.e. lower residence times will allow for higher treatable flow rates). The primary reason for this is the uncertainty in determining the true destruction efficiency in the field. Many technologies which achieved conversions in excess of $99 \%$ were also estimated to be producing chlorinated organic side products on the order of a few percent (no side products are observed with the thermal catalytic units used in support of the ISBR and ISH demonstrations). Nearly all of the emerging technologies can (or have the potential to) match or reduce the energy requirements observed for thermal catalytic oxidation. PCE and TCA destruction were more difficult with all of the destruction technologies and, therefore, showed an added energy requirement (or lower flow rate) to meet necessary efficiencies (these differences are noted where sufficient data was available). The numbers presented here are not meant as a final evaluation of the technology's capabilities, but, simply to initiate some assemblence of the realistic energy goals new technologies can potentially meet, are meeting or exceeding, or must meet.

The most energy intensive technologies appear to be the electric discharge techniques. These technologies, however, are probably the least developed of all the methods demonstrated. More recent studies with high-energy corona destruction at Battelle-PNL have shown that changes in the type and particle shape of the dielectric packing materials can significantly reduce energy requirements (by approximately 15\%) and residence times (use of supported noble metal catalyst pellets as the dielectric packing material reduced required residence times by a factor of 5 , however, such packing will impact the capital cost of treatment units) (Heath, et al., 1994). In addition, more recent tests have revealed that the energy density required for adequate destruction drops with scale-up of the reactors. The cold plasma technique suffered from considerable losses in the power supply (approximately 75 to $80 \%$ efficient) and to dielectric losses in the Pyrex cell liners (note that the power efficiency observed in the field was less than fifty percent). In addition, energy density requirements for PCE are more than an order of magnitude above that required for TCE (reported energy densities of approximately 35 to $40 \mathrm{~J} / \mathrm{h}$ for $95 \%$ reduction of TCE in dry air, Evans, et al., 1993). The silent discharge technology may also benefit by operating at lower pressures (i.e. on the vacuum side of the SVE unit) to lower required energy densities and reduce thermal stresses on the dielectric. An improved method of comparing the energy requirements for non-thermal plasma processing technologies was introduced by Rosocha (1994). This method is based on the assumption that the reduction in concentration is proportional to an exponential function of the applied energy density (based on the energy delivered to the gas). The constant is termed an "e-folding" factor since it describes the energy density required to reduce the concentration of a particular compound by $1 / \mathrm{e}$. Data analysis shows that the proportionality constant, or "e-folding" factor, is independent of initial concentration and, therefore, allows for comparisons on an equal footing. This method can also be applied to thermal treatment processes.

Photocatalytic and photolytic systems appear to offer a reduced energy requirement. The former systems require further studies aimed at catalyst and light optimization combined with reactor design issues related to mass transfer limitations (e.g. the bulk of the catalyst in the annular space does not receive sufficient UV light to generate the active sites and only those gas molecules which reach this region are readily attacked). The latter systems are plagued primarily by high 
selectivities to less desirable chlorinated organics. This may be addressed with better reactor design and/or with the combined use of photosensitive oxidants.

The energy requirements for the ozone enhanced oxidation best exhibit the characteristic discussed previously. Namely, energy use drops proportionally with concentration (i.e. ozone production requirements drop). At lower concentrations, this technology has energy requirements comparable to thermal catalytic oxidation. Vendor quoted capital costs for a 100 and $300 \mathrm{scfm}$ unit at the concentrations listed in the table are approximately $\$ 280 \mathrm{~K}$ to $\$ 289 \mathrm{~K}$ respectively, which includes the blower and caustic scrubbing equipment.

Regenerative adsorption is probably one of the most concentration dependent technologies. The higher the concentration, the shorter the breakthrough time, and, consequently, the greater the regeneration frequency. Conversely, adsorbent loadings (and consequently, bed size) are highly vapor concentration dependent, with maximum weight percent loadings varying by as much as an order of magnitude (e.g. 5 to 50 percent). As concentrations drop to below $100 \mathrm{ppm}$, this technology becomes very competitive for large waste sites were a decoupled process is viable (i.e. one regeneration unit serving several adsorption beds at different wells). There are additional costs involved with handling, storing, and shipping the recovered solvent. These costs can be reduced somewhat by the market value of the solvents. However, related to this same issue and not previously discussed is the requirement for a caustic scrubber for full scale destruction technologies. The costs involved with handling caustic and spent caustic solutions (the latter of which will contain some chlorinated organics potentially above disposal limits) may be equivalent to costs involved with handling pure liquid product. Additional information on the use of regenerative adsorption systems (both performance and economic based) can be found in Engleman, et al., 1992 and in a report generated for DOE by the GE Corporate Research and Development Center, Schenectady, New York, 1994.

\subsection{Unresolved Technical Issues}

Unresolved technical issues are strongly linked to estimates of the true cost for these new technologies. Since decisions are usually made based on cost, it is important to ensure that performance is not forgotten. A number of the unresolved technical issues for the emerging technologies have been discussed above and in the results presented in the previous chapter. This section will serve to focus the issues that are generic to a number of the technologies.

There are two primary unresolved technical issues related to the free radical destruction technologies. First is the formation of side products which are typically more hazardous than the feed CVOC's and occasionally more refractory towards further oxidation. Many of the new technologies have succumbed to admitting to the formation of phosgene and the chloroacetic acids (from chlorides). Often, these products are written off as readily scrubbed from the effluent in caustic scrubbers. This is definitely true for phosgene which is readily hydrolyzed. The acetic acids, however, may not degrade as quickly in these solutions. These tests, however, also revealed the formation of significant quantities of more highly chlorinated organic side products (including chloroform, carbon tetrachloride, pentachloroethane, and hexachloroethane), all of which are more regulated and toxic than either TCE or PCE. All of the free radical techniques 
had more difficulty in destroying TCA, which is a saturated chlorocarbon with at least three chlorine's on one carbon atom (as the chlorinated side products listed above are). Energy densities and residence times can be increased to deal with these more recalcitrant compounds, but power use estimates already show that these technologies do not have much energy to spare in comparison to thermal techniques. Beyond the technical solutions, consideration must be given to public perception which may connect the issue of toxic by-products with the current fear of incinerators.

The second major issue for the free radical techniques is also true for other destruction technologies. Extended tests at near full scale must be performed to truly confirm the technologies' reliability. As an example, catalyst and heating rod replacement costs were presented in Table 7.2 for thermal catalytic oxidation units. Similar part replacements are unknown for the emerging technologies: e.g. catalyst and/or lamp replacement for the photocatalytic or photolytic systems; electrode and dielectric replacement for the electric discharge techniques. In addition, lifetimes for materials of construction in the harsh environment of chlorine, oxygen, and oxychloride radicals are unknowns. Furthermore, power supplies for the more energetic techniques will have limited lifetimes and are appreciable capital cost items. Clearly, further extended testing is warranted to determine these critical factors. 
Table 7.1 Summary of Energy Requirements and Capital Costs for VNID Catalytic Oxidation Units

\begin{tabular}{|c|c|c|c|c|c|}
\hline $\begin{array}{c}\text { Operating } \\
\text { Unit }\end{array}$ & $\begin{array}{c}\text { Design / } \\
\text { Operating } \\
\text { Flow Rate } \\
\text { (scfm) }\end{array}$ & $\begin{array}{c}\text { Heater } \\
\text { Power } \\
\text { (kW) } \\
\text { (@) operating } \\
\text { How rates) }\end{array}$ & $\begin{array}{c}\text { Average } \\
\text { Destruction } \\
\text { Eff. (\%) } \\
\text { (typ. feed conc'n } \\
\text { Ppmv) }\end{array}$ & $\begin{array}{c}\text { Observed } \\
\text { kW-hr/kg } \\
\text { Destroyed }\end{array}$ & $\begin{array}{c}\text { Capital } \\
\text { Cost } \\
\text { (SK) }\end{array}$ \\
\hline ISBR & $530 / 235$ & $44(3)$ & $\begin{array}{c}95.6 \\
\text { (PCE:167) } \\
\text { (TCE: } 77)\end{array}$ & 74 & $79(6)$ \\
\hline ISH(1) $^{(1)}$ & $180^{(2)}$ & $29(4)$ & $\begin{array}{c}80.6(5) \\
\text { (PCE: 200) } \\
\text { (TCE: 50) } \\
\text { (TCA: 35) }\end{array}$ & 52 & $118^{(7)}$ \\
\hline
\end{tabular}

1) Unit equipped with recuperative heat exchanger (approximate efficiency: 40\%)

2) Unit not equipped with variable speed drive, vapor extraction well gas diluted with ambient air.

3) Based on $\mathrm{kW}-\mathrm{hr}$ meter

4) Based on maximum SCR output (at steady state, unit uses from 65 to 80 percent of maximum power)

5) Efficiency is lower due to catalyst by-pass

6) For oxidation unit only, includes $\$ 22 \mathrm{~K}$ for catalyst (catalyst loading based on design flow rate)

7) Includes SVE piping/equipment/instrumentation and additional controls not included with ISBR unit; also includes \$8K for catalyst

Table 7.2 Estimate of Total Operating Cost for ISH Thermal Catalytic Oxidation Unit

\begin{tabular}{|c|c|c|c|}
\hline Item Description & $\begin{array}{c}\text { Yearly Cost } \\
(\$)\end{array}$ & $\begin{array}{c}\text { Cost per kg } \\
(\$)\end{array}$ & Percentage of Total Cost \\
\hline Capital $^{(1)}$ & 13,443 & 3.07 & 22.8 \\
\hline Replacement Parts ${ }^{(2)}$ & 8,600 & 1.96 & 14.6 \\
\hline Labor (3) & 21,000 & 4.80 & 35.7 \\
\hline Energy $^{(4)}$ & 15,894 & 3.63 & 26.9 \\
\hline TOTAL & 63,137 & 13.46 & 100 \\
\hline
\end{tabular}

(1) Assumes thermal catalytic oxidation unit comprises $70 \%$ of total capital cost of $\$ 118 \mathrm{~K}$, unit amortized for 10 years at $10 \%$.

(2) Catalyst and $1 / 2$ of heating rod elements.

(3) 500 total hours per year (includes one hour per day monitoring) at $\$ 40 / \mathrm{hr}$ fully loaded plus 0.05 misc parts.

(4) Based on operation for 328.5 days/year at $80 \%$ of maximum rated power (equivalent to $4,379 \mathrm{~kg}$ of CVOC's per year). 
Table 7.3 Comparison of Energy Requirements for Demonstrated Technologies

\begin{tabular}{|c|c|c|}
\hline Technology & $\begin{array}{c}\text { Power use per } 100 \text { scfm } \\
(\mathrm{kW})\end{array}$ & Comments \\
\hline $\begin{array}{c}\text { Thermal Catalytic } \\
\text { Calculated } \\
\text { Observed } \\
\text { ISBR Unit } \\
\text { ISH Unit }\end{array}$ & $\begin{array}{l}16.9 \\
18.6 \\
16.1\end{array}$ & $\begin{array}{l}\text { Based on } 0.90 \text { heat efficiency and } 40 \% \text { heat } \\
\text { recovery }\left(450^{\circ} \mathrm{C} \text { operating temp.)) }\right. \\
\text { No heat recovery exchanger } \\
\text { ISH unit unable to meet destruction efficiency } \\
\text { for PCE due to suspected catalyst by-pass. } \\
\text { Uses } 80 \% \text { of max. power at steady-state. }\end{array}$ \\
\hline Vapor-Phase Photolvtic & 5.2 & $\begin{array}{l}\text { Based on } 4 \text { lamps operating at pulse frequency } \\
\text { of } 5 \mathrm{~Hz}\end{array}$ \\
\hline $\begin{array}{c}\text { Photocatalytic } \\
\text { NuTech } \\
\text { Univ. of Wisconsin }\end{array}$ & $\begin{array}{r}4.8 \\
22.7\end{array}$ & $\begin{array}{l}\text { Based on } 72 \text { lamp (100W each) reactor with } \\
\text { quoted } 150 \text { scfim capacity. Field unit did not } \\
\text { meet } 95 \% \text { destruction efficiency at } \geq 25 \text { scfin } \\
\text { Based on } 40 \mathrm{~W} \text { lamp for } 5 \mathrm{lpm} \text { annular tube } \\
\text { reactor. Does not include added energy for } \\
\text { elevated temperature operation }\end{array}$ \\
\hline $\begin{array}{l}\text { Electric Discharge } \\
\text { High-Energy Corona } \\
\text { Cold Plasma }\end{array}$ & $\begin{array}{c}32 \text { (TCE) } \\
167 \text { (PCE) } \\
\text { 324* (mixture) } \\
7 \text { (TCE) }\end{array}$ & $\begin{array}{l}\text { Field test unit used approximately } 12 \text { to } 15 \\
\text { kW at } 42 \text { scfin maximum. TCA destruction } \\
\text { efficiency not included. } \\
\text { Based on cell energy density of } 50 \mathrm{~W} / \mathrm{pm} \\
\text { (corrected for } 7 \mathrm{~kW} \text { delivered to gas per } 16 \\
\mathrm{~kW} \text { input)*. Field unit experienced power } \\
\text { supply problems. Biased heavily by PCE and } \\
\text { TCA. }\end{array}$ \\
\hline Enhanced Ozone & $\begin{array}{l}45 \\
15 \\
\end{array}$ & $\begin{array}{l}1000 \text { ppmv total CVOC } \\
300 \text { ppmv total CVOC (or } 45 \mathrm{~kW} \text { at } 300 \\
\text { scim) }\end{array}$ \\
\hline Carbon Regeneration & 6 & $\begin{array}{l}\text { Based on } 4 \text { hour regeneration cycle per } 12 \\
\text { hours at } 45 \mathrm{~kW}\end{array}$ \\
\hline
\end{tabular}

* Based on the "e-folding" factor of $1.5 \mathrm{~kJ} /$ liter for the field data and a $70 \%$ power efficiency, this value would be $261 \mathrm{~kW}$ for $95 \%$ destruction of the CVOC mixture (see text and Rosocha, 1994 for description of "e-folding" factor). 


\subsection{SUMMARY}

All of the technologies tested at the SRS proved or exhibited strong potential as viable methods for treating off-gas streams containing chlorinated organics. Most are applicable to moderate flow rate streams (typically less than one thousand $\mathrm{cfm}$ ) with concentrations ranging from 50 to 3000 ppmv. These conditions are typical for soil vapor extraction applications. Each technology varies in its stage of development towards complete commercialization. Most of the tests conducted under this program were of a very short and periodic nature (e.g. one to three weeks of operation during normal shift hours). Future testing efforts should focus on fewer technologies with more extended continuous operation. A testing program of this nature is especially critical for the emerging technologies that must prove their reliability under such conditions to be deemed ready for commercialization. Most of the technologies tested involved innovative destruction techniques. All of them except thermal catalytic oxidation, produce by-products that are more hazardous than the targeted chlorinated compounds. This finding revealed a need for improved sampling techniques to identify and quantify all potential by-products produced in the destruction technologies (there are proven and emerging methods for accomplishing this goal, but the time and expense involved was beyond the scope of this program).

The free-radical oxidation processes are relatively immature in their development process and require additional extended tests at near full scale to adequately determine their reliability. Early results are encouraging though as they can potentially require less energy and/or offer concentration dependent energy use relative to thermal techniques. This can be especially critical to remediation applications where concentrations will vary (drop off) significantly with time. In addition, all of the methods appear to offer greater CVOC conversion than thermal processes (typically greater than $99 \%$ ) and exhibited a characteristic trend in ease of destruction: TCE $>$ PCE $>$ TCA. A primary unresolved technical issue involves the formation of chlorinated side products including phosgene, chloroacetic acids, chloroform, carbon tetrachloride, pentachloroethane, and hexachloroethane. These incomplete decomposition products are more regulated, toxic, and typically more refractory towards further oxidation. This issue must be solved before these processes can be commercially viable and publicly acceptable.

The thermal catalytic processes are encouraging. When the optimum space velocity and temperature are used, destructions greater than ninety-nine percent were achieved for PCE, TCE, and TCA (the ease of destruction for thermal techniques are somewhat reversed vs free radical techniques with TCA $>$ TCE $>\mathrm{PCE}$, although some of the TCA is only partly converted to 1,1DCE). There are slightly detectable amounts of incomplete conversion products but none have been detected with the VNID's operable units. This technique, however, becomes energy intensive as CVOC concentrations drop below $100 \mathrm{ppmv}$. This process will meet the requirements of the Clean Air Act Amendments and will ostensibly be more favorable than activated carbon or incineration. Many sites, including the SRS, are choosing thermal catalytic oxidation for controlling emissions for the soil venting of CVOCs. 
The temporary and pilot scale nature of these tests did not warrant the addition of acid scrubbing equipment. However, to take full advantage of the mass flow rate capabilities of the destruction technologies, caustic scrubbers to remove the hydrochloric acid produced must be considered. While such technology is commonplace in industry, it could significantly impact economic decisions. The time and cost involved with handling fresh and spent scrubbing solutions can be equivalent to the cost incurred for solvent handling for recycling technologies discussed below. Furthermore, unreacted chlorinated organics and side products may accumulate in the solutions to an extent that their land disposal may be restricted (e.g. they would be classified as hazardous waste).

The separation processes are good for recovering liquid phase CVOCs. This technology is especially applicable to lower concentration streams (e.g. in the latter stages of remediation where mass transfer limitations cause a drop off in removal rates). There are still technical problems associated with the co-collection of water, limited adsorbent lifetimes, autocatalytic oxidation reactions (with activated carbon systems), and potential breakdown of the organics during regeneration. The first three issues can be reduced with the use of new synthetic adsorbents. The primary unresolved issue, however, is not technical and involves the liability associated with handling the CVOCs for recycling. Under current law, the liquid CVOC recovered in remediation of a waste site is considered hazardous waste until an entity purchases the solvent for reuse (there are additional uncertainties pertaining to classification as waste or product related to further processing of the recovered solvents to separate out water and/or individual components). Until it is resold, the generator of the waste/product is responsible for proper handling and storage which can carry considerable additional costs. Furthermore, while there is a present market for recovered chlorinated organics, long term remediation schemes are gambling on a continued favorable market in the future as well as a stable regulatory environment. Due to the presence of several hidden costs involved with these nontechnical issues, this technology may not be economically favored but is easily the "greenest" solution when consideration of reduced emissions of carbon dioxide and hydrochloric acid are given or an account of the energy saved versus production of virgin solvents is made.

Biodestruction technologies may provide a means of reducing the load on other treatment systems but are generally better suited for aqueous waste treatment. The technology tested at the SRS involved the transfer of TCE from the vapor phase to water, a clearly thermodynamically unfavorable process given the Henry's constants and solubilities of chlorinated compounds. This limitation, combined with the slower reaction rates for biodestruction would inadversely affect scale-up of this technology. Alternative biotreatmnet techniques (e.g. filtration) which "mimic" the carbon adsorption/regeneration concept are probably more applicable to off-gas streams. 


\subsection{REFERENCES}

Adams, J.Q., and Clark, R.M., "Evaluating the Costs of Packed-Tower Aeration and GAC for Controlling Selected Organics." Journal AWWA, 1991, 83, No.1, 49-57

Basta, N., "The Recycling Loop Closes for Solvents." Chem. Eng., 1991, 98, No.6, 43

Birmingham, J.G. and R.R. Moore, "Reactive Bed Plasma Air Purification." U.S. Patent No. $4,954,320,1990$

Bromberg, L., D.R. Cohn, M. Koch, R.M. Patrick, and P. Thomas, "Decomposition of Dilute Concentrations of Carbon Tetrachloride in Air by an Electron Beam Generated Plasma." Phys. Lett. A., 1993, 173, 293-299

Blystone, P.G., M.D. Johnson, W.R. Haag, P.F. Daley, "Advanced Ultraviolet Flashlamps for the Destruction of Organic Contaminants in Air." presented at ACS, I\&EC Division Special Symp., October 1-3, 1991, Atlanta, GA

Blystone, P.G., M.D. Johnson, W.R. Haag, "Destruction of Organic Contaminants in Air Using Advanced Ultraviolet Flashlamps." presented at Air \& Waste Manage. Assoc., 85th Annual Mtng., June 21-26, 1992a, Kansas City, MO

Blystone, P.G., B. Mass, and W.R. Haag, "VOC Recovery from Air Streams Using Specialized Adsorbents: A New Economical Recycling Option." Proceedings of the ACS I\&EC Special Symposium on Emerging Technologies for Hazardous Waste Management, 1992b, Atlanta, GA

Buck, F.A.M., and E.L. Seider, "Commercial Vapor Treatment Processes." Paper Presented at Symposium on Soil Venting, Houston, TX, April 29 to May 1, 1991. (Paper may be obtained from King, Buck \& Associates, Inc., San Diego, CA)

CH2M Hill, "A/M-Area Vadose Zone Characterization Project Report." prepared for the Westinghouse Savannah River Co. under Contract No. AX720936, Document No. WSRC-RP-901335,1990

Dempsey, C.R. and Oppelt, E.T., "Incineration of Hazardous Waste: A Critical Review Update." J. Air \& Waste Management Assoc., 1993, 43 (January), 25-73

Engleman, V.S. and L.L. Hunter, "Recovery of Volatile Organic Compounds from Soil Remediation Sites at the Savannah River Site (SRS)." prepared for the Idaho National Engineering Laboratory, EG\&G Idaho, Inc. by SAIC Corp., San Diego, CA, September, 1992, under Subcontract No. C90-102743 
Evans, D., L.A. Rosocha, G.K. Anderson, J.J. Coogan, and M.J. Kushner, "Plasma remediation of trichloroethylene in silent discharge plasmas." J. Appl. Phys., 1993, 74, No. 9, 5378-5386

Fischer, A.M., Winterle, J.S., and Mill, T., "Primary Photochemical Processes in Photolysis Mediated by Humic Substances." Photochemistry of Environmental Aquatic Systems, American Chemical Society, 1987.

Frost, A.C., Sawyer, J.E., Summers, J.C., Shah, Y.T., and Dassori, C.G., "Kinetics and Transport Parameters for the Fixed-Bed Catalytic Incineration of Volatile Organic Compounds." Environ. Sci. Technol., 1991, 25, 2065-2070

GE Research \& Development Center, "Organic Sponges for Cost-Effective CVOC Abatement." prepared for U.S. Dept. of Energy, Morgantown Energy Tech. Cntr., Morgantown, VA, May, 1994, under Contract No. DE-AC21-92MC29110

Glaze, W.H., and Kang, J.W., "Advanced Oxidation Processes. Description of a Kinetic Model for the Oxidation of Hazardous Materials in Aqueous Media with Ozone and Hydrogen Peroxide in a Semibatch Reactor." I\&EC Research, 1989a, 28, 1573-1580

Glaze, W.H., and Kang, J.W., "Advanced Oxidation Processes. Test of a Kinetic Model for the Oxidation of Organic Compounds with Ozone and Hydrogen Peroxide in a Semibatch Reactor." I\&EC Research, 1989b, 28, 1580-1587

Glaze, W.H., Kang, J.W., and Chapin, D.H., "The Chemistry of Water Treatment Processes Involving Ozone, Hydrogen Peroxide and Ultraviolet Radiation." Ozone Science \& Engineering, $1987,9,335-352$

Gong, R., and Kenner, T.C., "A Qualitative Analysis of the Effects of Water Vapor on MultiComponent Vapor-Phase Carbon Adsorption." J. Air \& Waste Management Assoc., 1993, 43, 864-872

Haselow, J.S., J. Rossabi, T.R. Jarosch, "Emerging Technologies for Abatement of Atmospheric Chlorinated Volatile Organic Compound Emissions." presented at Proceedings of the 1992 Waste Management and Environmental Sciences Conference, April 9-11, 1992, San Juan, Puerto Rico (also released as Westinghouse Savannah River Co. Document No. WSRC-MS-92-0

Heath, W., S. Barlow, T. Bergsman, D. Lessor, T. Orlando, A. Peurrung, and R. Shah, "Development and Analysis of High-Energy Corona Process for Air Purification." presented at the 1st International Conference on Advanced Oxidation Technologies for Water and Air Remediation, June 25-30, 1994, London, Ontario, Canada

Herbert, K.J., "Catalysts for Volatile Organic Compound Control in the 1990's." Paper presented at the 1990 Incineration Conference, May 14-18, 1990, San Diego, CA 
Jain, N.K., "Brayton Cycle Solvent Recovery", Paper presented at the Air \& Waste Management Assoc. 85th Annual Mtng., June 21-26, 1992, Kansas City, MO

Jarosch, T.R., R.S. Beleski, and D. Faust, "Final Report: In-Situ Radio Frequency Heating Demonstration." Westinghouse Savannah River Co. Document No. WSRC-TR-93-673, 1993, prepared for the U.S. Dept. of Energy under Contract No. DE-AC09-89SR18035

Johnson, L.D., "Detecting Waste Combustion Emissions." Environ. Sci. Tech, 1986, 20, 223

Keller, J.O., Gemmen, R.S., and Barr, P.K., "Premixed Combustion in an Oscillating/Resonant Flow Field. Part I:Experimental Investigation." Proceedings of the 1990 ASME Winter Annual Meeting, Nov. 25-30, 1990, Dallas, Tx.

Kittrell, J.R, Quinlan, C.W., and Eldridge, J.W., Direct Catalytic Oxidation of Halogenated Hydrocarbons, J. Air \& Waste Manage. Assoc., 1991, 41, 1129-1133

Koffskey, W.E., Lykins, B.W., "GAC Adsorption and Infrared Reactivation: A Case Study." Journal AWWA, 1990, 82, No.1, 48-56

Lombard, K.H., J.W. Borthen, and T.C. Hazen, "The Design and Management of System Components for In-Situ Methanotrophic Bioremediation of Chlorinated Hydrocarbons at the Savannah River Site." Proceedings of the In-Situ and On Site Bioreclamation Symposium: Air Sparging, Ed. R.E. Hinchee, Lewis Publishers, 1993

Looney, B.B., Hazen, T.C., Kaback, D.S., Eddy, C.A., "Full Scale Field Test of the In Situ Air Stripping Process at the Savannah River Integrated Demonstration Test Site (U). "Westinghouse Savannah River Company Report No. WSRC-RD-91-22, June 29, 1991.

Marine, I.W. and H.W. Bledsoe, "Supplemental Technical Data Summary: M-Area Grounwater Investigation." E.I. du Pont de Nemours \& Co., DPSTD-84-112, October, 1984, prepared for the US Dept. of Energy under Contract No. DE-AC09-76SR00001

Nimlos M.R. and T.A. Milne, "Direct Mass Spectrometric Studies of the Destruction of Hazardous Wastes. 1. Catalytic Steam Re-Forming of Chlorinated Hydrocarbons." Environ. Sci. Technol., 1992. 26, 545-552

Nimlos, M.R.; Jacoby, W.A.; Blake, D.M; Milne, T.A., "Direct Mass Spectrometric Studies of the Destruction of Hazardous Wastes. 2. Gas-Phase Photocatalytic Oxidation of Trichloroethylene over $\mathrm{TiO}_{2}$ : Products and Mechanisms." Environ. Sci. Technol., 1993, 27, 732740

Nunez, C.M., G. H. Ramsey, W. H. Ponder, J.H. Abbott, L. E. Hamel, and P. H. Kariher, "Corona Destruction: An Innovativc Control Technology for VOCs and Air Toxics." J. Air \& Waste Manage. Assoc., 1993, 43, 242-247 
Ollis, D.F., Pelizzetti, E., and Serpone, N., "Photocatalyzed Destruction of Water Contaminants." Environ. Sci. and Technol., 1991, 25, 1522-1529

Palazzolo, M.A., Jamgochian, C.L., Steinmetz, J.I., and Lewis, D.L., "Destruction of Chlorinated Hydrocarbons by Catalytic Oxidation." EPA/600/2-86/079, 1986

Rinko, J., and M. Traister, "Practical Considerations for the Selection of Pollution Control Equipment for VOC Emissions." Paper presented at the 81st Annual Air Pollution Control Association Meeting, June 19-24, 1988, Dallas, TX. (Paper may be obtained from O'Brien \& Gere Engineers, Inc., Syracuse, NY)

Rosocha, L.A., "Nonthermal Plasma Applications to Pollution Control and Environmental Remediation." First International Conference on Advanced Oxidation Technologies, London, Ontario, Canada, June 25-30, 1994 (Los Alamos National Laboratory Report: LA-UR-94-2115)

Rossabi, J., J.S. Haselow, "Technology Status Report: Off-Gas Treatment Technologies for Chlorinated Volatile Organic Compound Air Emissions." Westinghouse Savannah River Co. Document No. WSRC-RP-92-473, 1991

Saaty, R.P. and S.R. Booth, "In-Situ Bioremediation: Cost Effectiveness of a Remediation Technology Field Tested at the Savannh River Integrated Demonstration Site." Los Alamos National Laboratory Report No. LA-UR-94-XXXX, August, 1994

Shah, R.R., R.E. Garcia, J.T. Jeffs, J.W. Virden, and W.O. Heath, "Initial Field Test of HighEnergy Corona Process for Treating a Contaminated Soil Off-Gas Stream." 1994, Pacific Northwest Laboratory Document No. PNL-9224

Speth, T.F., and Miltner, R.J., "Technical Note: Adsorption Capacity of GAC for Synthetic Organics." Journal AWWA, 1990, 82, No.2, 72-75

Steverson, E.M., "Provoking a Firestorm: Waste Incineration." Environ.Sci. Technol., 1991, 25, 1808-1814

Strandberg, G.W., Donaldson, T.L., and Farr, L.L., "Degradation of Trichloroethene and trans1,2-Dichloroethylene by a Methanotrophic Consortium in a Fixed-Film, Packed-Bed Bioreactor." Environ.Sci. Technol., 1989, 23, 1422-1425

Takacs, L., and Moilanen, G. L., "Simultaneous Control of PCDD/PCDF, $\mathrm{HCl}$ and $\mathrm{NO}_{\mathrm{x}}$ Emissions from Municipal Solid Waste Incinerators with Ammonia Injection." J. Air \& Waste Manage. Assoc., 1991, 41, 716-722.

van der Vaart, D.R., W.M. Vatavuk, and A.H. Wehe, "Thermal and Catalytic Incinerators for the Control of VOC's." J. Air Waste Mànage. Assoc., 1991a, 41, No. 1, 92-98 
van der Vaart, D.R., W.M. Vatavuk, and A.H. Wehe, "The Cost Estimation for Thermal and Catalytic Incinerators for the Control of VOC's." J. Air Waste Manage. Assoc., 1991b, 41, No. 4, 497-501

Varma, R., Nandi, S.P., and Cleaveland, D.C., "Microwave-Assisted Chemical Process for Treatment of Hazardous Waste." DOE/HWP-28 ANL-87-20, 1987.

Varma, R, Nandi, S.P., and Katz, J.D., "Detoxification of Hazardous Waste Streams Using Microwave-Assisted Fluid-Bed Oxidation." Materials Research Society Spring Meeting Symposium, April 16-21, 1990, San Francisco, CA.

Varma, R, and Nandi, S.P., "Oxidative Degradation of Trichloroethylene Adsorbed on Active Carbons: Use of Microwave Energy." LA-UR-91-1552 DE91 013656, 1991, Los Alamos National Laboratory, Los Alamos, NM

Vancit, M.A., Howle, R.H., Herndon, D.J., and Shareef, S.A., "Air Stripping of Contaminated Water Sources - Air Emissions and Controls." EPA-450/3-87-017, 1987.

Virden, J.W., W.O. Heath, S.C. Goheen, M.C. Miller, G.M. Mong, and R.L. Richardson, "HighEnergy Corona for the Destruction of Volatile Organic Contaminants in Process Off-Gases." 1992, Presented at Spectrum '92, Boise, Idaho, Pacific Northwest Laboratory Document No. $P N L-S A-20741$

Yamazaki-Nashida, S., H.W. Read, K.J. Nagano, T.R. Jarosch, C.A. Eddy, S. Cervera-March, and M.A. Anderson, "Gas Phase Photocatalytic Degradation on TiO2 Pellets of Volatile Chlorinated Organic Compounds from a Soil Vapor Extraction Well." J. Soil Contam., 1994, 3, No. 3 (in press), also released as Westinghouse Savannah River Co. Document No. WSRC-MS93-415

Yamazaki-Nashida, S., K.J. Nagano, L.A. Phillips, S. Cervera-March and M.A. Anderson, J. Photochem. Photobiol. A: Chem., 1993, 70, 1073-1081

Wekhof, A., "Treatment of Contaminated Water, Air and Soil With UV Flashlamps." Environmental Progress, 1991, 10, 241-247

Zafiriou, O.C., "Marine Organic Photochemistry Previewed." Marine Chemistry, 1977, 5, 497522

Wijmans, J.G., Kaschemekat, J., Davidson, J.E., and Baker, R.W., "Treatment of OrganicContaminated Wastewater Streams by Pervaporation." Environmental Progress, 1990, 9, No.4, 262-268. 


\section{APPENDIX}

List of Contacts for Participants in the Off-Gas Treatment Testing Program

Free Radical Oxidation Technologies

Vapor-Phase Photolytic Destruction

Michael L. Wilkey, P.E.

Argonne National Laboratory

Energy Systems Division

9700 S. Cass Ave.

Argonne, IL 60439

(708) 252-9240

\section{Photocatalytic Oxidation}

Marc A. Anderson

Professor, Water Chemistry Program

University of Wisconsin - Madison

660 N. Park St.

Madison, WI 53706-1484

(608) 262-2674

\section{Electric Discharge Techniques}

Dr. Louis A. Rosocha

Los Alamos National Laboratory

CST-18, MS E548

Los Alamos, NM 87545

(505) 667-8493
Paul Blystone

Purus, Inc.

2713 North First St.

San Jose, CA 95134

(408) $955-1000$
Bob Henderson Matrix Photocatalytic, Inc. 22 Pegler Street London, Ontario N5Z 2B5 CANADA (519) 660-8669
William O. Heath

Battelle - Pacific Northwest Laboratory

P.O. Box 999, MS P7-41

Richland, WA 99352-0999

(509) 376-0554

\section{Ozone Enhanced Oxidation}

Jack D. Zeff

Ultrox International

2435 S. Anne St.

Santa Ana, CA 92704-5308

(714) 545-5557 


\section{Separation Technologies}

Stephen Priebe

EG\&G Idaho National Engineering

Laboratory

Energy Programs

P.O. Box 1625

Idaho Falls, ID 83415

(208) 526-0898

\section{Biodestruction Technology}

Christopher J. Berry

Westinghouse Savannah River Co.

Savannah River Technology Center

Bldg 704-08T

P.O. Box 616

Aiken, SC 29808

(803) 725-6413

\section{Thermal Oxidation Technologies}

\section{Thermal Catalytic Oxidation}

Daryl M. VanBenschoten

Johnson Matthey

Catalytic Systems Division

436 Devon Park Dr.

Wayne, PA 19087-1816

(215) 341-8541
Joseph C. Enneking

NUCON International, Inc.

P.O. Box 291517000 Huntley Rd.

Columbus, $\mathrm{OH} 43229$

(614) $846-5710$
Iris Freidel

Allied Signal

Industrial Catalysts

P.O. Box 580970

Tulsa, OK 74158-0970

(918) 266-1400 